\title{
AGRONOMIC OUTCOMES OF PRECISION IRRIGATION MANAGEMENT TECHNOLOGIES WITH VARYING COMPLEXITY
}

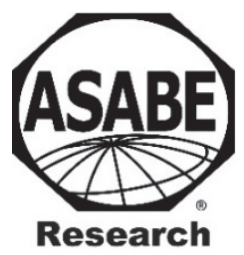

Kelly R. Thorp ${ }^{1, *}$, Sebastian Calleja ${ }^{2}$, Duke Pauli², Alison L. Thompson ${ }^{1}$, Diaa Eldin Elshikha ${ }^{3,4}$

${ }^{1}$ USDA-ARS U.S. Arid Land Agricultural Research Center, Maricopa, Arizona, USA.

${ }^{2}$ School of Plant Sciences, University of Arizona, Tucson, Arizona, USA.

${ }^{3}$ Department of Biosystems Engineering, University of Arizona, Tucson, Arizona, USA

${ }^{4}$ Department of Agricultural Engineering, Mansoura University, Al Mansoura, Egypt.

* Correspondence: kelly.thorp@usda.gov

\section{HighLIGHTS}

- Cotton yield and water productivity were measured for different precision irrigation management solutions.

- Agronomic improvements from site-specific irrigation based on spatial FAO-56 crop coefficient data were minor.

- Thermal remote sensing data from unoccupied aircraft systems were able to identify crop water limitations.

- Integrated sensing and modeling tools that can achieve intended agronomic outcomes should be prioritized.

\begin{abstract}
Diverse technologies, methodologies, and data sources have been proposed to inform precision irrigation management decisions, and the technological complexity of different solutions is highly variable. Additional field studies are needed to identify solutions that achieve intended agronomic outcomes in simple and cost-effective ways. The objective of this study was to compare cotton yield and water productivity outcomes resulting from different solutions for scheduling and conducting precision irrigation management. A cotton field study was conducted at Maricopa, Arizona, in 2019 and 2020 that evaluated the outcomes of four management solutions with varying technological complexity: (1) a stand-alone evapotranspiration-based soil water balance model with field-average soil parameters (MDL), (2) using site-specific soil data to spatialize the modeling framework (SOL), (3) driving the model with spatial crop coefficients estimated from an unoccupied aircraft system (UAS), and (4) using commercial variable-rate irrigation technology for site-specific irrigation applications (VRI). Soil water content data and thermal UAS data were also collected but used only in post hoc data analysis. Applied irrigation, cotton fiber yield, and water productivity were statistically identical for MDL and SOL. As compared to $M D L$, the UAS crop coefficient approach significantly reduced applied irrigation by $7 \%$ and $14 \%$ but also reduced yield by 5\% and 26\% in 2019 and 2020, respectively $(p=0.05)$. In 2019 only, the VRI approach maintained yield while significantly reducing applied irrigation by $8 \%$ compared to $M D L$, and water productivity was significantly increased from 0.200 to $0.211 \mathrm{~kg} \mathrm{~m}^{-3}$ when one outlier datum was removed $(p=0.05)$. Post hoc data analysis showed that crop water stress information, particularly from UAS thermal imaging data, would likely benefit the irrigation scheduling protocol. Efforts to develop integrated sensing and modeling tools that can guide precision irrigation management to achieve intended agronomic outcomes should be prioritized and will be relevant whether irrigation applications are site-specific or uniform.
\end{abstract}

Keywords. Cotton, Crop coefficient, Drone, FAO-56, Irrigation scheduling, Remote sensing, Site-specific irrigation, Soil mapping, Unoccupied aircraft system, Variable-rate irrigation, Water stress. \footnotetext{
(c) (1) $\left(\begin{array}{l}\text { The authors have paid for open access for this article. This } \\ \text { wY NC ND }\end{array}\right.$ NonCommercial-NoDerivatives 4.0 International License.

Submitted for review on 10 November 2021 as manuscript number NRES 14950; approved for publication as a Research Article by the Natural Resources \& Environmental Systems Community of ASABE on 23 December 2021.

Mention of company or trade names is for description only and does not imply endorsement by the USDA. The USDA is an equal opportunity provider and employer.
}

$\mathrm{P}$ recision irrigation management requires supporting technologies to determine spatially and/or temporally optimized irrigation recommendations. Diverse technologies are now being developed to support precision irrigation management decisions, including: (1) models of soil water balance, evapotranspiration (ET), and/or crop yield (Booker et al., 2015; González Perea et al., 2018; Haghverdi et al., 2016; Kelley et al., 2020; Rudnick and Irmak, 2014; Stone and Sadler, 2016; Stone et al., 2019; Thorp, 2020; Thorp et al., 2017); (2) sensor-based measurement and mapping of soil water content and soil water holding characteristics (Barker et al., 2017; De Lara et al., 2018; 
Hedley and Yule, 2009a, 2009b; Lo et al., 2017; Thompson et al., 2007; Vellidis et al., 2008); (3) remote and proximal sensing techniques to estimate crop coefficients, ET, or crop water stress from terrestrial, airborne, or satellite platforms (Alchanatis et al., 2010; Barker et al., 2018; Bhatti et al., 2020; Bian et al., 2019; Falkenberg et al., 2007; French et al., 2015; Hunsaker et al., 2015; O'Shaughnessy et al., 2011; Peters and Evett, 2007; Sadler et al., 2002a); and (4) algorithms and hardware for site-specific irrigation control and decision support (Andrade et al., 2020a, 2020b; Evans et al., 2012; Evett et al., 2020a; Kranz et al., 2012; McCarthy et al., 2013; O'Shaughnessy et al., 2015; Sui et al., 2020). The diversity of available technologies suggests the existence of multiple pathways for achieving precision irrigation management in practice. Naturally, some technologies are likely better suited for the task than others, yet few studies have made broad comparisons or demonstrated that one solution achieves better agronomic outcomes (e.g., crop yield, irrigation reductions, or water productivity) compared to another. Furthermore, as many technologies are complementary and may be integrated, some solutions may involve a higher level of technological complexity (and therefore expense) than others. However, few studies have identified whether such additional complexity is justified by concomitant improvement in agronomic or economic outcomes. As growers are increasingly overwhelmed with technological choices that all promise to improve yield and reduce costs and environmental impact, research must demonstrate how specific solutions for precision irrigation management lead to improved outcomes in simple and cost-effective ways.

The following cascade of increasingly complex precision irrigation management solutions can be envisioned. First, as a baseline scenario, consider a grower who uses no technology for irrigation management, and whose decisions are based solely on traditional field scouting and weather reports. For this grower, a first step toward adoption of precision irrigation management technology may be to use a simple ET-based irrigation scheduling tool (Hunsaker et al., 2005) or to install a few soil water content sensors in the field (Vellidis et al., 2008). Many examples of irrigation scheduling software and smartphone apps are now freely available from cooperative extension services (Migliaccio et al., 2016), and a variety of soil water content sensors are commercially available at a reasonable cost. As a second step, the grower may invest in a map of soil characteristics (Lo et al., 2017), which would provide information on spatial soil water holding limits and allow irrigation decisions considering multiple soil types across the field. Such soil mapping services have been available for many years, although their use for site-specific irrigation management remains uncommon (Evans et al., 2013). Third, consider that the grower now seeks information on plant growth and water stress during the growing season, which could be obtained from a number of commercially available groundbased sensors, small unoccupied aircraft systems (sUAS), or satellite imaging technology (Barker et al., 2018). This information could be incorporated into the scheduling tool to adjust, for example, the crop coefficients for site-specific ET-based irrigation recommendations (Hunsaker et al., 2015); however, the integration of remote sensing data products with irrigation industry tools remains uncommon (Evett et al., 2020b). Finally, consider that the grower now invests in irrigation equipment for conducting site-specific irrigation and can spatially implement the recommendations from the information technologies described previously. Such irrigation systems are now commercially available, although the rate of adoption has been low because the agronomic and economic benefits of the technology have not been effectively demonstrated (Evans and King, 2012; Evans et al., 2013; Neupane and Guo, 2019; O'Shaughnessy et al., 2019). The preceding example is indicative of the great investment, both financially and in terms of learning the technology, required for growers to adopt precision irrigation management, particularly for those growers now using no technology whatsoever. Research should clarify which technologies offer the greatest opportunity to achieve desired agronomic or economic outcomes, such that the approach can be simplified, and costs can be reduced for the grower as much as possible.

A common misconception is that more technological complexity should naturally provide better outcomes. With precision irrigation management, this has manifested in debates on whether site-specific irrigation technology, as compared to simpler irrigation technologies with no spatial component, is justified by a real benefit or is merely a "solution looking for a problem" (Evans and King, 2012; Evans et al., 2013). For example, King et al. (2006) found that potato (Solanum tuberosum L.) yield and water productivity increased by $4 \%$ with site-specific irrigation as compared to conventional uniform irrigation, but the results were not statistically different and did not economically justify a benefit for site-specific irrigation. Similarly, Stone et al. (2015) found no statistical differences in peanut (Arachis hypogaea L.) yield or water productivity when comparing sitespecific and conventional uniform irrigation. Lo et al. (2016) studied the potential pumpage reduction among 49,224 fields irrigated by center pivots in Nebraska, finding opportunity for only $1.3 \%$ reductions in pumpage volume by using site-specific irrigation to mine undepleted soil water. Cotton (Gossypium hirsutum L.) irrigation studies using the USDA-ARS Irrigation Scheduling Supervisory Control and Data Acquisition system (Evett et al., 2020a) for sitespecific irrigation achieved significantly greater water productivity than the Arkansas Irrigation Scheduler in one of two seasons, but seed cotton yield was not different among the treatments in either year (Vories et al., 2021). In field comparisons of site-specific and conventional uniform irrigation, Sui and Yan (2017) found that site-specific irrigation reduced irrigation amounts by $25 \%$ while increasing soybean (Glycine max L. Merr.) yield by $2.8 \%$ and maize (Zea mays L.) yield by $0.8 \%$ with concomitant improvements in water productivity, although yields were not significantly different among the irrigation treatments. Generally, it is unclear whether the mediocre performance of sitespecific irrigation is due to uncertainties and failures in the supporting technologies or if there are realistically only minor benefits to be gained. While the promises of precision and/or site-specific irrigation to achieve agronomic benefits are theoretically justified, additional research is necessary to develop the required supporting technologies, 
demonstrate benefits in practical field settings, and identify appropriate simplifications that maximize benefit while reducing cost and complexity.

The overall goal of this study was to assess cotton yield and water productivity outcomes using different methodologies and technologies to inform precision irrigation management decisions for an Arizona cotton field trial. An ETbased soil water balance model, as described in FAO-56 (Allen et al., 1998), formed the basis for different irrigation treatments. Specific objectives were to (1) compare model recommendations with field-average versus site-specific soil data, (2) compare standard trapezoidal crop coefficient data with that computed from sUAS-based estimates of fractional crop cover, (3) compare conventional uniform and site-specific irrigation management for Arizona cotton production, and (4) assess opportunities for soil water content data and sUAS-based thermal imaging to identify crop water stress.

(a)

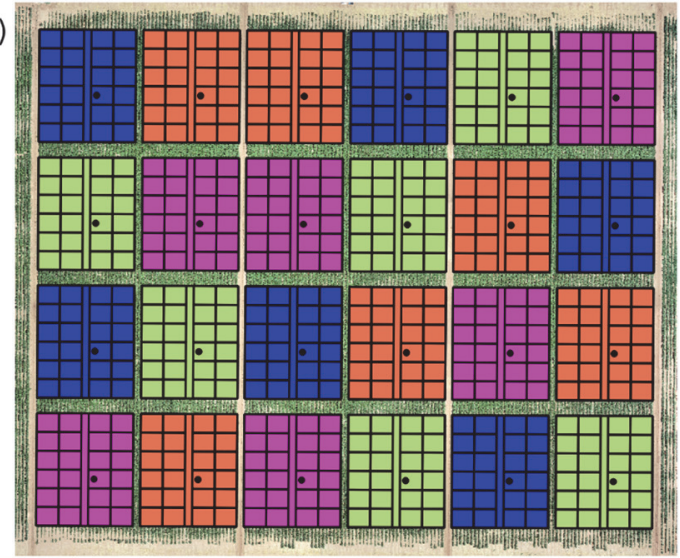

(c)
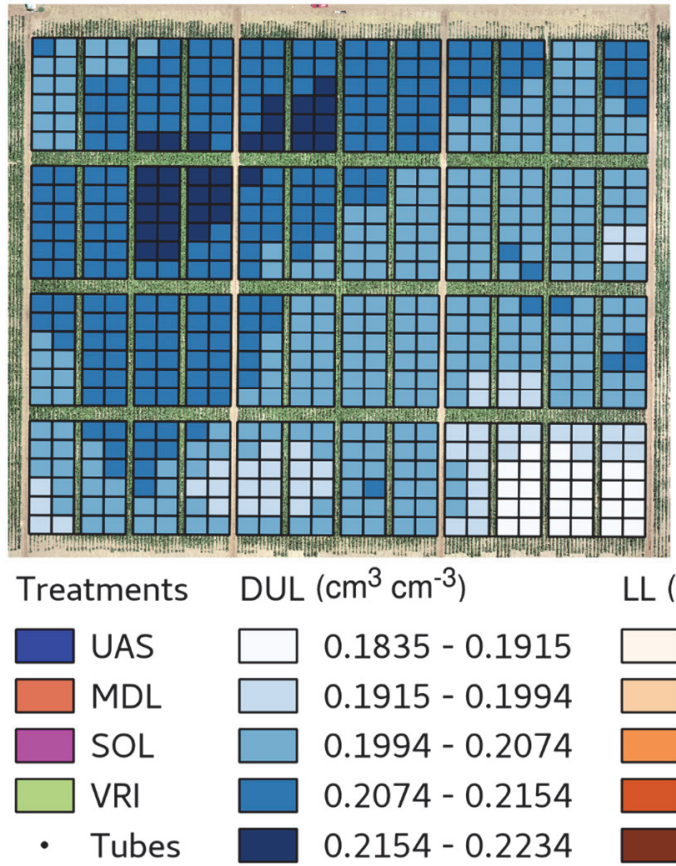

DUL $\left(\mathrm{cm}^{3} \mathrm{~cm}^{-3}\right)$

$0.1835-0.1915$

$0.1915-0.1994$

$0.1994-0.2074$

$0.2074-0.2154$

$0.2154-0.2234$ (b)

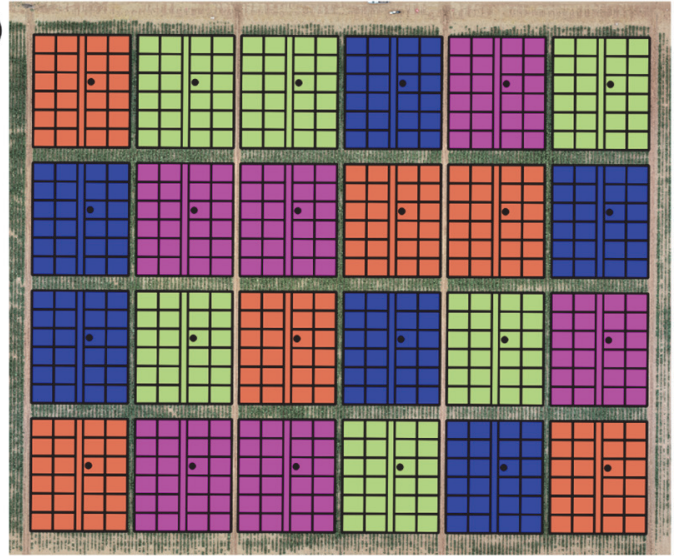

\section{Materials ANd Methods}

FIELD EXPERIMENT

A cotton field experiment was conducted at the University of Arizona's Maricopa Agricultural Center (MAC) near Maricopa, Arizona $\left(33.079^{\circ} \mathrm{N}, 111.977^{\circ} \mathrm{W}, 360 \mathrm{~m}\right.$ above sea level) during the 2019 and 2020 cotton growing seasons (fig. 1). Four precision irrigation management treatments were tested, which involved varying complexities of technologies to determine irrigation schedules and administer irrigation applications (table 1). A randomized block design was used with six replicated blocks and a total of 24 plots, requiring a 2.8 ha field area. Each plot was $24.4 \mathrm{~m}$ ( 24 cotton rows) by $36 \mathrm{~m}$. For geospatial data analysis and site-specific irrigation applications, each plot was further subdivided into 24 zones, each sized $6 \mathrm{~m} \times 6 \mathrm{~m}$ (fig. 1). The simplest irrigation management treatment (MDL) used an ET-based FAO56 soil water balance model to schedule irrigation using field-average soil parameters and standard trapezoidal crop

(d)

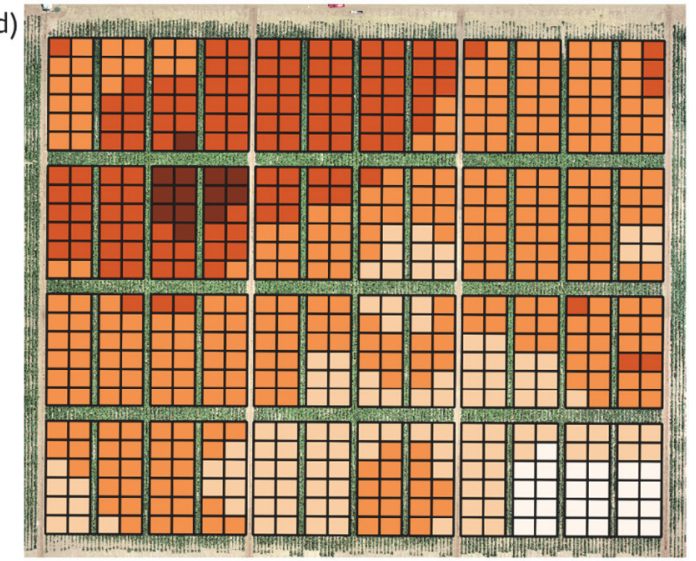

$\left.\mathrm{m}^{3} \mathrm{~cm}^{-3}\right)$
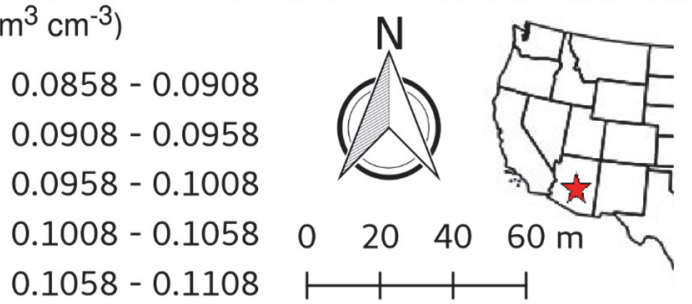

Figure 1. Plot maps for a precision irrigation management experiment during the (a) 2019 and (b) 2020 cotton growing seasons at Maricopa, Arizona. Four irrigation treatments tested the following technologies: (1) an FAO-56 model (MDL), (2) site-specific soil maps (SOL), (3) crop coefficients from an unoccupied aircraft system (UAS), and (4) site-specific, variable-rate irrigation technology (VRI). Plots were subdivided into 24 zones (each $6 \mathrm{~m} \times 6 \mathrm{~m}$ ), and soil variability was characterized from interpolations of the (c) drained upper limit (DUL) and (d) lower limit (LL). Soil water content was measured weekly using a neutron moisture meter at one access tube location in each plot. 
Table 1. Precision irrigation management treatments tested during the 2019 and 2020 cotton growing seasons at Maricopa, Arizona. Each treatment increased the complexity of technologies used to schedule and administer irrigation: (1) a stand-alone FAO-56 model (MDL), (2) adding site-specific soil data (SOL), (3) adding crop coefficients ( $\left.K_{c b}\right)$ from an unoccupied aircraft system (UAS), and (4) adding site-specific, variablerate irrigation applications (VRI).

\begin{tabular}{|c|c|c|c|c|}
\hline Treatment & Description & Soil Data & $K_{c b}$ Data & Irrigation Application \\
\hline MDL & ET-based FAO-56 soil water balance model & Field-average & Trapezoidal & Uniform \\
\hline SOL & Add spatial data for soil water holding limits & Site-specific & Trapezoidal & Uniform (2019), site-specific (2020) \\
\hline UAS & Add spatial data for basal crop coefficients $\left(K_{c b}\right)$ & Site-specific & UAS crop cover & Uniform \\
\hline VRI & Add VRI technology for site-specific irrigation applications & Site-specific & UAS crop cover & Site-specific \\
\hline
\end{tabular}

coefficient data. No geospatial information was incorporated into the irrigation management decisions for this treatment, and irrigation was applied uniformly across all MDL treatment areas. The second treatment (SOL) tested the addition of site-specific soil data, which were used to run the FAO56 model uniquely for each $6 \mathrm{~m} \times 6 \mathrm{~m}$ zone. In 2019, the median irrigation recommendation among zones was applied uniformly across the area of all six SOL plots. Based on the 2019 results, site-specific irrigation was tested for the SOL treatment in the 2020 growing season, where each $6 \mathrm{~m}$ $\times 6 \mathrm{~m}$ zone received its recommended irrigation schedule. The third treatment (UAS) tested the addition of weekly sUAS imagery for estimation of crop cover and FAO-56 basal crop coefficients $\left(K_{c b}\right)$, which were used with the sitespecific soil data to run the FAO-56 model uniquely for each $6 \mathrm{~m} \times 6 \mathrm{~m}$ zone. The median irrigation recommendation among zones was applied uniformly across the area of all six UAS plots. The fourth treatment (VRI) tested the addition of commercial technology for administering site-specific irrigation via a lateral-move overhead irrigation system. While the irrigation rates for all treatments were managed via this irrigation system, only the VRI treatment (and SOL in 2020) involved spatially variable irrigation rates within the treatment area. For VRI management decisions, the FAO-56 model was run similarly as for the UAS treatment, but irrigation applications were administered based on the unique recommendation for each $6 \mathrm{~m} \times 6 \mathrm{~m}$ zone. In this way, the field study tested the agronomic outcomes of precision irrigation management strategies with varying and increasing technological complexity.

The environment for cotton production in the Arizona low desert is arid and hot. Data from an Arizona Meteorological Network (AZMET; http://ag.arizona.edu/azmet) weather station approximately $1.2 \mathrm{~km}$ from the field site demonstrated air temperature patterns during the two growing seasons (fig. 2). Daily minimum and maximum air temperatures regularly exceeded $25^{\circ} \mathrm{C}$ and $40^{\circ} \mathrm{C}$, respectively, from July through August, corresponding to days of year (DOY) 182 to 243. This coincided with the time of cotton reproductive development, when heat stress can cause flower abnormalities and abscission of bolls aged 3 to 5 days (Brown, 2008). As such, AZMET also provides daily information on Level 1 and Level 2 heat stress conditions based on air temperature and humidity. The number of days during July and August with Level 1 and Level 2 heat stress conditions was 27 and 18 in 2019 and 22 and 34 in 2020, respectively. The 2020 growing season was characterized by record-breaking mean air temperatures and consecutive heat stress days during the sensitive cotton reproductive period in July and August. Heat stress was also present in 2019 but with less severity than in 2020 . The cotton growing season also straddles the Arizona monsoon season in July and August, when relative humidity and dew point temperatures rise sharply (fig. 2). As measured by the AZMET weather station, growing season precipitation from April through September (DOY 91 to 273) amounted to 53 and $4 \mathrm{~mm}$ during the 2019 and 2020 growing seasons, respectively, while precipitation during the monsoon season in July and August amounted to 26 and $3 \mathrm{~mm}$, respectively. In comparison, standardized short crop reference ET $\left(\mathrm{ET}_{o s}\right)$ from April through September amounted to 1352 and $1424 \mathrm{~mm}$ in the 2019 and 2020 growing seasons, respectively. Thus, irrigation was required to meet evaporative demand, and dryland production was not realistic.

Cover crops were grown in the winter months between cotton seasons to reduce soil nutrient variability and improve soil quality. The field was prepared for cover crop planting by deep ripping, moldboard plowing, disking, and either planing or laser leveling. Barley (Hordeum vulgare L.) was
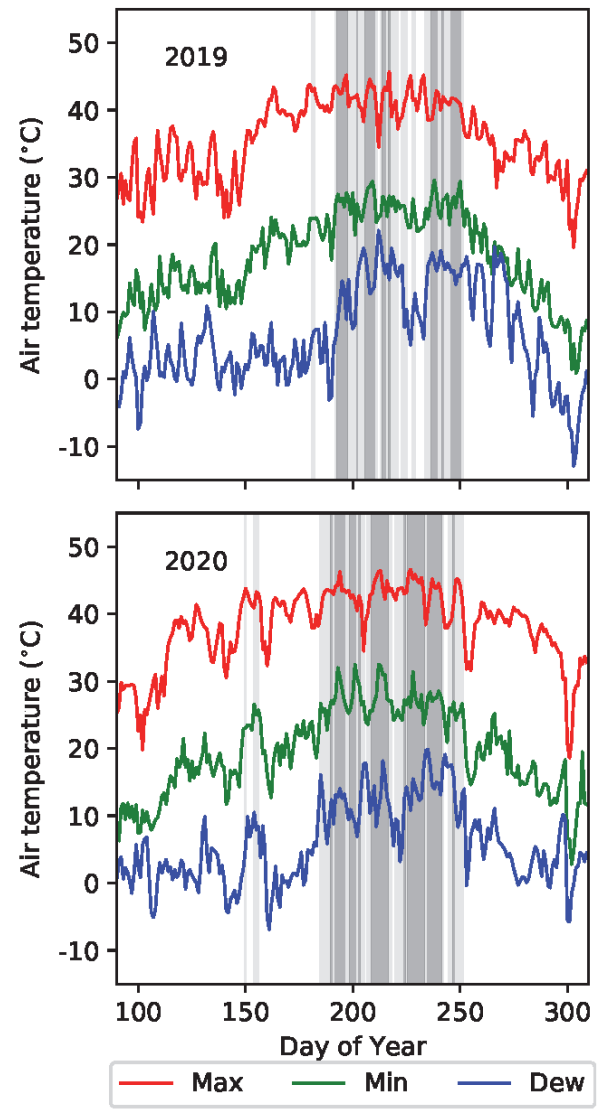

Figure 2. Daily maximum, minimum, and average dew point air temperatures during 2019 and 2020 cotton growing seasons from 1 April (day of year 91) through 31 October (day of year 304) at Maricopa, Arizona. Light and dark shaded regions indicate days with Level 1 and Level 2 heat stress, respectively. 
planted on 13 December 2018 (DOY 347) and 29 January 2020 (DOY 29) and terminated with glyphosate (RoundUp PowerMAX, Bayer CropScience, Monheim am Rhein, Germany) on 8 March 2019 (DOY 67) and 24 March 2020 (DOY 84) following manufacturer's recommendations for application decisions. The cover crops were fully irrigated until termination, but no fertilizer was applied.

Upland cotton (Gossypium hirsutum L., cv. 'NexGen 5007 B2XF', Americot, Inc., Lubbock, Tex.) was planted into the terminated barley cover crop using a no-till planter on 18 April 2019 (DOY 108) and 21 April 2020 (DOY 112). The variety was chosen based on its observed performance in Arizona fields during prior cotton growing seasons. The row orientation was north-south, and the row spacing was $1.02 \mathrm{~m}$. Final plant density after emergence was 6.9 and 10.0 plants $\mathrm{m}^{-2}$ in 2019 and 2020, respectively. Pre-emergent herbicide (Prowl H2O, BASF, Florham Park, N.J.) was applied to the soil surface on 8 April 2019 (DOY 98) and 9 April 2020 (DOY 100) following manufacturer's recommendations for application decisions. The herbicide was incorporated with light irrigation $(10 \mathrm{~mm})$ immediately after application. Following irrigation termination in early September, cotton was defoliated with thidiazuron and diuron (Ginstar EC, Bayer CropScience, Monheim am Rhein, Germany), and a boll opener containing ethephon and urea sulfate (CottonQuik, Nufarm Americas, Inc., Alsip, Ill.) was also applied according to manufacturer's recommendations. The defoliant and boll opener were applied on 4 October (DOY 277) and 18 October (DOY 291) in 2019 and on 25 September (DOY 269) and 16 October (DOY 290) in 2020.

\section{IRRIGATION MANAGEMENT}

As reported by Thorp et al. $(2017,2020)$, an overhead lateral-move sprinkler irrigation system (Zimmatic, Lindsay Corp., Omaha, Neb.) was installed at the field site in 2014. Advanced technology was later added to the irrigation machine, which permitted site-specific irrigation applications based on georeferenced irrigation maps uploaded to the machine's control panel (GrowSmart Precision VRI, Lindsay Corp., Omaha, Neb.). Irrigation rates were computed uniquely for each drop hose using information from (1) the user-provided application rate map, (2) two global positioning system (GPS) receivers on opposite ends of the lateral, and (3) a database of system characteristics, which included the position of each drop hose along the length of the lateral. The system used wireless communication among 88 nodes to relay information along the lateral, and each wireless node provided individual control for four drop hoses by adjusting the duty cycles of four electronic solenoid valves. The machine was equipped with $41.4 \mathrm{kPa}$ pressure regulators (PSR-6, Senninger, Clermont, Fla.) and $0.201 \mathrm{~L} \mathrm{~s}^{-1}$ nozzles (\#13.5, Senninger, Clermont, Fla.). The nozzles were spaced $1.02 \mathrm{~m}$ apart, located at the center of each cotton interrow area, and positioned to emit water less than $1.0 \mathrm{~m}$ above the soil surface. For uniform soil wetting prior to cotton emergence, spray pads giving a spray diameter of approximately $5.0 \mathrm{~m}$ were used. After cotton emergence, the spray pads were changed to a "bubbler" style, which emitted large droplets with a $0.3 \mathrm{~m}$ spray diameter at the center of each interrow area. In addition to reducing water loss to evaporation, the smaller spray diameter of the bubbler spray pads increased the spatial accuracy of irrigation applications relative to the intended application areas delineated in the georeferenced irrigation maps. Spatial application error with the site-specific irrigation machine was estimated to be less than $2.0 \mathrm{~m}$.

Uniform irrigation management was used during the preseason and to emerge the cotton crop. In 2019, $122 \mathrm{~mm}$ of pre-plant irrigation was applied over three days from 25 March (DOY 84) to 27 March (DOY 86); however, no pre-plant irrigation was applied in 2020. Reducing and eliminating pre-plant irrigation was a goal in the current and previous (Thorp et al., 2020) studies because this traditional practice was developed for surface-irrigated systems and has been deemed wasteful. After cotton planting, uniform irrigation was applied every few days with amounts ranging from 10 to $20 \mathrm{~mm}$ to emerge the crop and reduce soil surface crusting to prevent breakage of the emerging cotyledon. After emergence, uniform irrigation was applied approximately weekly at rates of 20 to $30 \mathrm{~mm}$ throughout May and until first square. The total amount of uniform irrigation applied in April and May was $147 \mathrm{~mm}$ in 2019 and $253 \mathrm{~mm}$ in 2020. In lieu of pre-plant irrigation in 2020, a larger amount of water was applied after planting during crop establishment. Prior to initiating water management treatments at first square, the field-average soil water content from the surface to $140 \mathrm{~cm}$ was $24.1 \%$ in 2019 and $24.0 \%$ in 2020 , meaning previous irrigation had raised the field-average soil water content above the drained upper limit (fig. 1).

\section{Irrigation Scheduling ModeI}

Irrigation recommendations for all treatments were obtained from different implementations of an ET-based daily soil water balance model as described in FAO-56 (Allen et al., 1998). Briefly, daily crop water use $\left(\mathrm{ET}_{c}\right)$ was calculated with the following equation:

$$
\mathrm{ET}_{c}=\left(K_{c b} K_{s}+K_{e}\right) \mathrm{ET}_{o s}
$$

where $\mathrm{ET}_{o s}$ is the standardized short crop reference evapotranspiration (Walter et al., 2005), $K_{e}$ is the soil water evaporation coefficient, and $K_{s}$ is the water stress coefficient for reducing daily transpiration during water-limited conditions. Required meteorological data for calculating $\mathrm{ET}_{o s}$ included the daily minimum and maximum air temperatures, average dew point temperature, solar irradiance, and wind speed (fig. 2). Weather data files for in-season irrigation scheduling were compiled in three parts: (1) past in-season data through yesterday, (2) a 7-day forecast from today forward, and (3) long-term average weather for days beyond the 7-day forecast. From the date of planting through yesterday, weather data were obtained from the AZMET station. From today through seven days into the future, local weather forecasting data were obtained from the National Digital Forecast Database (https://graphical.weather.gov/xml/rest.php). Beyond the 7-day forecast, weather data were specified as the average historical value from AZMET since the station was initiated in 1987.

For the MDL and SOL treatments (table 1), $K_{c b}$ time series were quantified using the standard trapezoidal crop coefficient curve (Allen et al., 1998) with initial, mid-season, 
and ending $K_{c b}$ quantified as $0.15,1.225$, and 0.5 , respectively. As recommended in FAO-56, maximum $K_{c b}$ at midseason was adjusted to 1.225 based on AZMET relative humidity and wind speed data. Based on Hunsaker et al. (2005), lengths of time between trapezoidal inflection points were specified as $35,50,46$, and 39 calendar days for the initial, development, mid-season, and late-season periods, respectively. The $K_{c b}$ time series for the UAS and VRI treatments (table 1) were constructed from sUAS imaging data, which were processed to estimate crop cover as discussed later. For all treatments, $K_{e}$ and $K_{s}$ coefficients were calculated as described in FAO-56. For $K_{s}$ in particular, calculations were based on a daily soil water balance methodology, where the drained upper limit (DUL, $\mathrm{cm}^{3} \mathrm{~cm}^{-3}$ ) and lower limit $\left(\mathrm{LL}, \mathrm{cm}^{3} \mathrm{~cm}^{-3}\right)$ defined the total plant-available water (TAW, mm) within the rooting depth $\left(Z_{r}, \mathrm{~m}\right)$ :

$$
\mathrm{TAW}=1000(\mathrm{DUL}-\mathrm{LL}) Z_{r}
$$

When TAW dropped below the readily available water $(\mathrm{RAW}=p \mathrm{TAW})$, the model reduced $K_{s}$ from 1.0, thereby reducing plant transpiration due to water stress (eq. 1). The model calculated $K_{s}$ as follows:

$$
K_{s}=\frac{\mathrm{TAW}-D_{i-1}}{(1-p) \mathrm{TAW}}
$$

where $D_{i-1}$ is the depth (mm) of root zone soil water depletion from the DUL at the end of the previous day, and $p$ is a constant $(p=0.65)$ representing the fraction of TAW that can be extracted without suffering water stress. The model calculated soil water status on day $i$ as follows:

$$
D_{i}=D_{i-1}-P_{i}-I_{i}+\mathrm{ET}_{c, i}+\mathrm{DS}_{i}
$$

where $D_{i}$ is the depth (mm) of root zone soil water depletion from the drained upper limit at the end of day $i, P_{i}$ and $I_{i}$ are the depths $(\mathrm{mm})$ of precipitation and irrigation received on day $i, \mathrm{ET}_{c, i}$ is the daily crop water use (mm, eq. 1), and $\mathrm{DS}_{i}$ is the depth $(\mathrm{mm})$ of water lost to deep seepage, which was calculated when water inputs caused TAW to be exceeded. This ET-based soil water balance model, as described in FAO-56 (Allen et al., 1998), was coded in Python (www.python.org) and used as a basis for all irrigation recommendations in this study.

\section{Soil Property Mapping}

Soil variability at the field site was characterized via a soil sampling effort at 160 locations during 2016 and 2017 (not shown). A tractor-mounted soil sampler (model 25-TS, Giddings Machine Co., Windsor, Colo.) was used to collect cylindrical soil samples $(0.04 \mathrm{~m}$ diameter $\times 0.4 \mathrm{~m}$ depth $)$ at five incremental soil profile depths centered at 0.2, 0.6, 1.0, 1.4, and $1.8 \mathrm{~m}$. Soil texture analysis was conducted in the laboratory using the hydrometer method of Gee and Bauder (1986), and the soil water holding limits (DUL and LL) of each sample were computed from texture data using the Rosetta pedotransfer functions (Zhang and Schaap, 2017). Ordinary kriging was used to spatially interpolate the DUL and LL at the central location of each $6 \mathrm{~m} \times 6 \mathrm{~m}$ zone within each plot (fig. 1). Geostatistics were conducted using the "geoR" package within the R Project for Statistical Computing software (www.r-project.org). The soil texture at the field site was primarily sandy loam and sandy clay loam with DUL between 0.19 and $0.22 \mathrm{~cm}^{3} \mathrm{~cm}^{-3}$ and LL between 0.09 and $0.11 \mathrm{~cm}^{3} \mathrm{~cm}^{-3}$. For the MDL treatment (table 1), field-average soil water limits $\left(0.205 \mathrm{~cm}^{3} \mathrm{~cm}^{-3}\right.$ for DUL and $0.098 \mathrm{~cm}^{3}$ $\mathrm{cm}^{-3}$ for LL) were input to the FAO-56 model. For the remaining treatments, the FAO-56 model was used to calculate soil water balances using the unique soil water limits for each of the $6 \mathrm{~m} \times 6 \mathrm{~m}$ zones in each plot (fig. 1).

\section{Crop Coefficient Estimation}

Basal crop coefficients $\left(K_{c b}\right)$ for input to the FAO-56 model were estimated from fractional crop cover $\left(f_{c}\right)$, which was mapped weekly with digital color images collected via an autopiloted sUAS. After crop emergence, a commercial quadcopter sUAS (Phantom 4 Pro, DJI, Shenzhen, China) was flown weekly over the field around solar noon. The sUAS was equipped with a 20-megapixel digital color camera with an $84^{\circ}$ field-of-view lens, one-inch complementary metal-oxide-semiconductor (CMOS) detector, and a red, green, and blue (RGB) color filtering system. Digital RGB images with a pixel resolution of $5472 \times 3648$ and 8 bits per color channel were collected and saved to the microSD card onboard the sUAS. The camera was positioned at a nadir view angle during overflights. Flight plans were created with a flight planning mobile application (Pix4DCapture, Pix4D SA, Lausanne, Switzerland) installed on a tablet computer (iPad, Apple Inc., Cupertino, Cal.), which was connected to the sUAS remote controller. Forward and lateral image overlaps of $80 \%$ were used to construct flight plans, and the flight altitude was specified as $61 \mathrm{~m}$ above ground level. After uploading the flight plans, the flight vehicle automated the flight control and collection of images. During the 2019 growing season, 27 overflights were conducted from 25 April (DOY 115) to 7 November (DOY 311). During the 2020 growing season, 28 overflights were conducted from 22 April (DOY 113) to 27 October (DOY 301). Flights were typically conducted on Mondays or early in the week to facilitate data processing turnaround for informing irrigation management decisions later in the week.

Several ground control points (16 in 2019 and 12 in 2020) were established around the field area by staking plastic bucket lids into the ground, and the geographic coordinates of each lid were measured using real-time kinematic (RTK) global positioning equipment with $\mathrm{cm}$-level accuracy (model 5800, Trimble Inc., Sunnyvale, Cal.). A custom Python script was developed to manually relate the geographic coordinates of ground control points with the sUAS image coordinates where bucket lids appeared, and this information was later used for image georeferencing. Open-source photogrammetry software (OpenDroneMap, www.opendronemap.org) that incorporated structure-from-motion (SfM) algorithms was used to compute georeferenced RGB orthomosaics of the field area. The orthomosaics were further processed to convert the RGB data to the hue, saturation, and intensity (HSI) color space using the algorithms developed by Thorp and Dierig (2011). The hue data typically demonstrated a bimodal distribution with soil and plant pixels clearly differentiated (fig. 3), so the hue band was used 
(a)

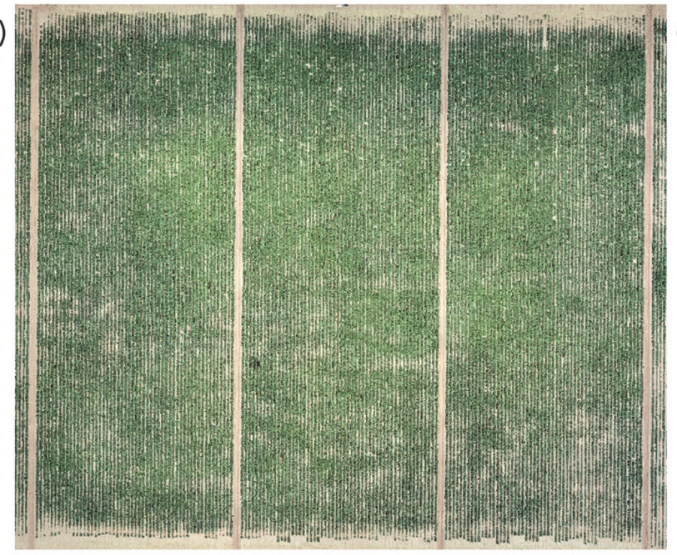

(c)

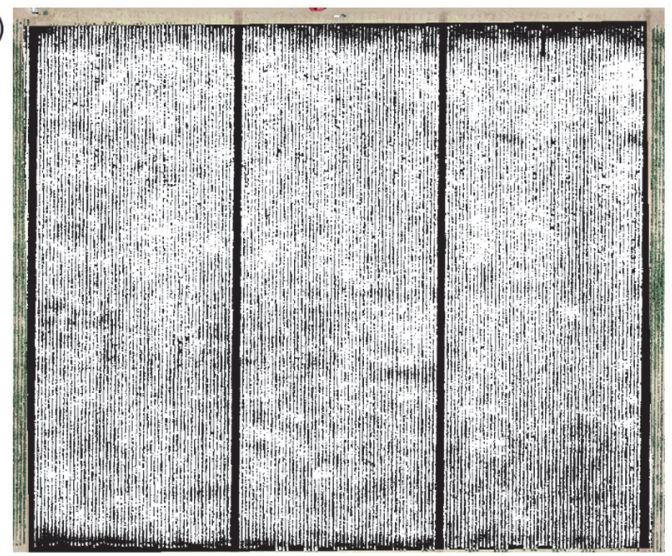

(b)

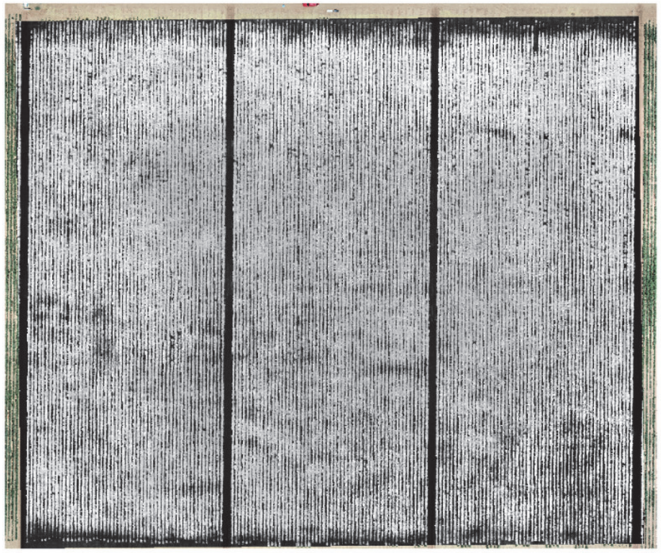

(d)
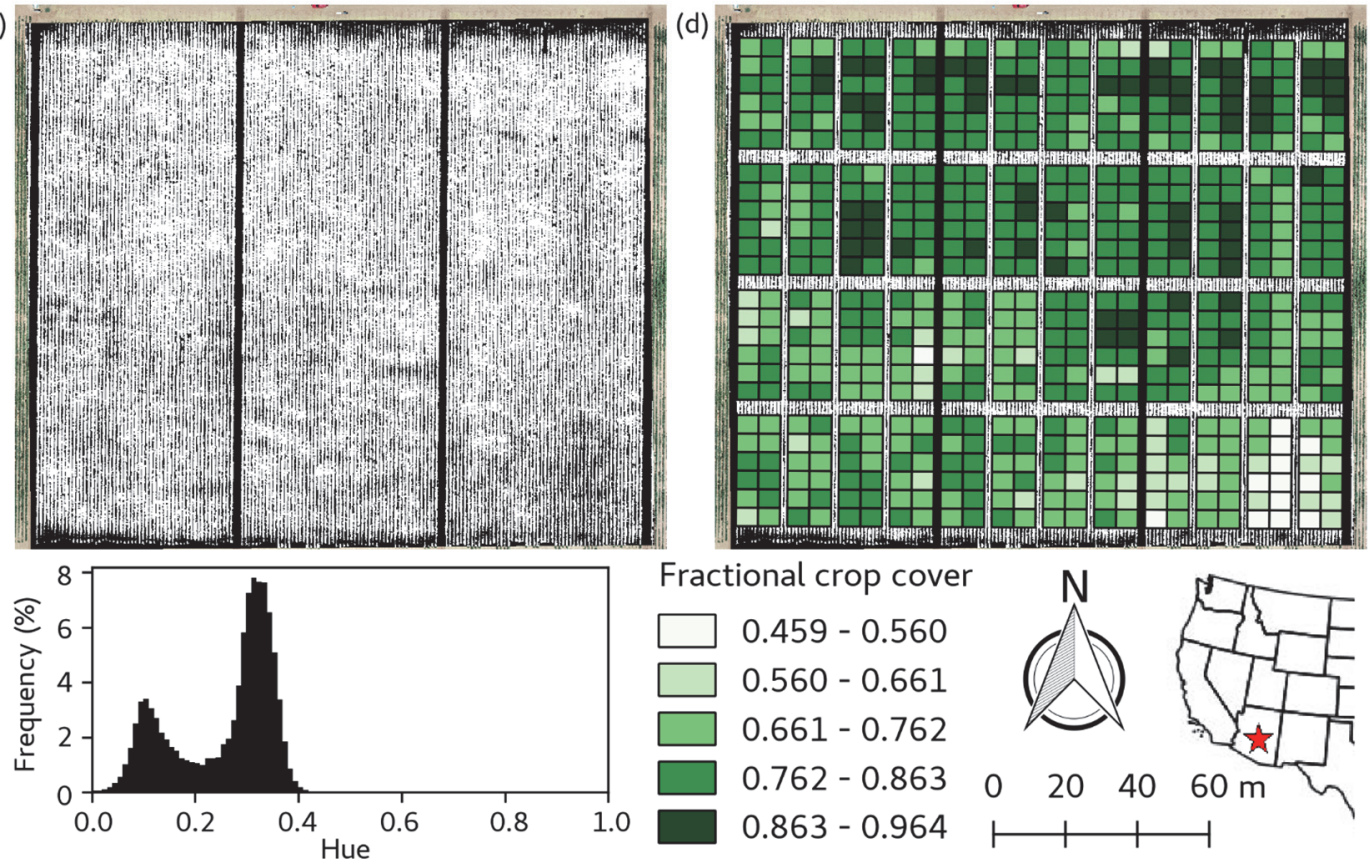

Fractional crop cover

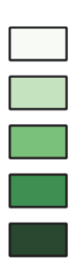

$0.459-0.560$

$0.560-0.661$

$0.661-0.762$

$0.762-0.863$

$0.863-0.964$

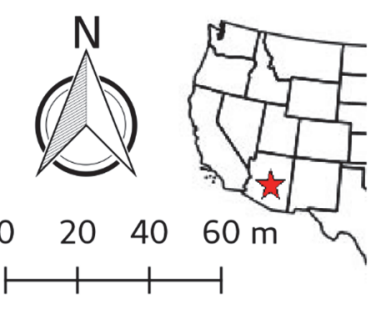

Figure 3. Photogrammetry software produced (a) georeferenced orthomosaics of red, green, and blue (RGB) images collected via a small unoccupied aircraft system (sUAS). The RGB orthomosaics were converted to the hue, saturation, and intensity (HSI) color space prior to extraction of the (b) hue band, which best separated plant and soil pixels (histogram in lower left). Classification of the hue band produced a (c) binary image of soil (black) and plant (white) pixels, which was used to compute (d) fractional crop cover within $6 \mathrm{~m} \times 6 \mathrm{~m}$ zones on the dates of sUAS overflights. The example in this figure was based on sUAS data collected on 15 July 2019 (day of year 196).

for segmentation of soil and plant pixels. Hue data were randomly sampled from the hue band and assigned to soil (hue $=0.01$ to 0.13 ) or cotton plant (hue $=0.26$ to 0.41 ) classes, and the data were used to train an expectation likelihood supervised classification algorithm. The trained classifier was then used to segment the entire hue band to produce a binary image with pixels classified as either soil or cotton plant (fig. 3). Zonal statistics were computed from the segmented image data to obtain the total number of pixels within each $6 \mathrm{~m} \times 6 \mathrm{~m}$ zone (approximately 138,160 pixels per zone) as well as the number of pixels classified as plant. Fractional crop cover $\left(f_{c}\right)$ was computed from these data as the ratio of plant pixels and total pixels for each $6 \mathrm{~m} \times 6 \mathrm{~m}$ zone (fig. 3). A Python script that incorporated the "osgeo", "cv2", and "rasterstats" packages was designed to complete these image processing and geospatial data analysis tasks. As the season progressed and additional sUAS flights were conducted, a time series $f_{c}$ plot was developed for each zone.
To fill daily gaps between weekly $f_{c}$ from sUAS data and to project future $f_{c}$, a daily logistic growth model was fit to the available sUAS $f_{c}$ data each week:

$$
\frac{d f_{c}}{d t}=r f_{c}\left(1-\frac{f_{c}}{f_{c, \max }}\right)
$$

where $r$ describes the growth rate and $f_{c, \max }$ is the maximum value that $f_{c}$ attains. This differential equation has an analytical solution:

$$
f_{c}=\left(\frac{c e^{r\left(t-t_{0}\right)}}{1+\frac{c}{f_{c, \text { max }}} e^{r\left(t-t_{0}\right)}}\right)
$$




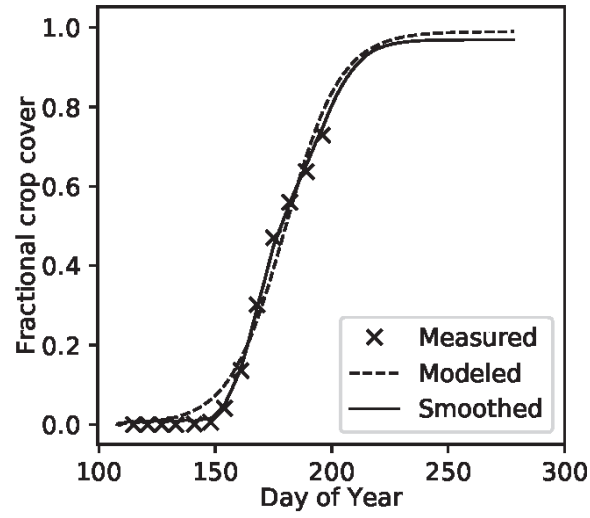

Figure 4. Weekly fractional crop cover measurements from unoccupied aircraft system overflights were modeled using a daily logistic growth equation, and Kalman smoothing was used to merge the measured and modeled data. The Kalman-smoothed fractional cover time series were used to estimate basal crop coefficients $\left(K_{c b}\right)$ for an irrigation scheduling model. Measured data for this example were provided through 15 July 2019 (DOY 196) from one $6 \mathrm{~m} \times 6 \mathrm{~m}$ zone (zone 54-10).

where

$$
c=\frac{f_{c, \text { max }} f_{c, 0}}{f_{c, \text { max }}-f_{c, 0}}
$$

and $f_{c, 0}$ is $f_{c}$ at the initial day of year $\left(t_{0}\right)$.

The growth model (eq. 6) was parameterized for each $6 \mathrm{~m} \times 6 \mathrm{~m}$ zone by adjusting the four model parameters $\left(t_{0}, f_{0}, f_{c, \max }\right.$, and $\left.r\right)$ to minimize error between modeled $f_{c}$ and the sUAS $f_{c}$ estimates (fig. 4). Subsequently, equation 5 with fitted parameters was incorporated into an unscented Kalman smoothing algorithm to develop daily $f_{c}$ time series that considered uncertainty in both the measured and modeled $f_{c}$ data. To achieve reasonable time series as assessed visually, the $f_{c}$ state transition variance was set to 0.0002 while the measurement variance was set five times higher at 0.001 . With these settings, the Kalman-smoothed $f_{c}$ time series somewhat favored the measured data over the modeled data (fig. 4). A Python script was developed to conduct this analysis, which incorporated a differential evolution optimizer within the "scipy" package for model fitting and the "pykalman" package for unscented Kalman smoothing. The Kalman-smoothed daily $f_{c}$ data were finally rescaled between the minimum and maximum $K_{c b}(0.15$ and 1.225 , respectively) to provide sUAS-based $K_{c b}$ time series for input to the FAO-56 irrigation scheduling model for UAS and VRI treatments only (table 1).

\section{Site-Specific Irrigation}

Typically, a $24 \mathrm{~h}$ turnaround time was required to (1) collect sUAS images, (2) process ground control point data, (3) generate orthomosaics (usually left to run overnight), (4) produce $f_{c}$ estimates (figs. 3 and 4), (5) process $K_{c b}$ time series, and (6) run the FAO-56 irrigation scheduling scenarios. Furthermore, water deliveries to the field site via concrete-lined canals required $24 \mathrm{~h}$ advanced notice. As such, Monday through Wednesday of each week were used for data collection and processing and for submitting water orders, and Thursday and Friday were established as the weekly irrigation days. For all irrigation management treatments, the FAO-56 model was used to compute the depth of water to be applied on Thursday and Friday without exceeding the DUL on those days and such that the soil water was depleted by no more than $45 \%$ through the following Wednesday. The $6 \mathrm{~m} \times 6 \mathrm{~m}$ zone that required the greatest amount of water established the $100 \%$ rate for the week, and the speed of the irrigation machine and number of passes was computed to provide the appropriate irrigation depth to the $100 \%$ zone. To minimize potential for overland flow and encourage infiltration at the application site, the speed of the irrigation system was maximized while also requiring an even number of passes such that the machine could be returned to its designated parking location. (Furthermore, based on visual observations of irrigation events, planting cotton into the terminated barley cover crop with no tillage improved infiltration as compared to an adjacent cotton study that used pre-plant tillage practices.) Irrigation depths for all other zones were controlled by the site-specific irrigation system. Using geographic information software, a shapefile was created to delineate the $6 \mathrm{~m} \times 6 \mathrm{~m}$ zones for treatments receiving site-specific irrigation and the full plot area for treatments receiving uniform irrigation (table 1), and rate percentages were assigned to each area to deliver the appropriate irrigation depth. The shapefile was then imported into the commercial software provided by the manufacturer of the site-specific irrigation equipment (FieldMAP, Lindsay Corp., Omaha, Neb.), and the software produced a proprietary irrigation prescription file, which was uploaded to the control panel on the irrigation machine. Typically, the same site-specific irrigation prescription was used for all passes of the irrigation machine during a given week, except for fertigation events.

\section{Fertilizer Management}

Following the recommendations of Bronson et al. (2021), liquid urea ammonium nitrate (UAN 32-0-0) was uniformly applied in three split applications in both growing seasons, amounting to seasonal nitrogen application rates of $149 \mathrm{~kg}$ $\mathrm{N} \mathrm{ha}^{-1}$ in 2019 and $136 \mathrm{~kg} \mathrm{~N} \mathrm{ha}^{-1}$ in 2020. A fertigation trailer, which included a fertilizer tank, metering pump, and gasoline-powered generator, was hitched to the lateral-move irrigation machine, and fertilizer was injected into the overhead irrigation pipe. During fertigation events, the irrigation machine was operated at $25 \%$ of full speed, which applied $\mathrm{N}$ fertilizer with $20 \mathrm{~mm}$ of water. To ensure uniform fertilizer application, no site-specific irrigation management was conducted during fertigation events. Fertilizer application dates were 30 May (DOY 150), 21 June (DOY 172), and 11 July (DOY 192) in 2019 and 4 June (DOY 156), 26 June (DOY 178), and 17 July (DOY 199) in 2020.

\section{Field MEASUREMENTS}

Soil water content was measured weekly via a field-calibrated neutron moisture meter (model 503, Campbell Pacific Nuclear, Martinez, Cal.). After planting, steel access tubes were installed centrally in each plot (fig. 1) using a tractormounted soil sampler (model 25-TS, Giddings Machine Co., Windsor, Colo.). From early May to early October, the neutron moisture meter was deployed on a weekly basis (approximately 20 times per growing season) to measure soil water content from 0.1 to $1.9 \mathrm{~m}$ in $0.2 \mathrm{~m}$ incremental depths at each access tube. During post hoc data analysis, the soil 
water content data, along with estimates of DUL and LL at each access tube (fig. 1), were used to calculate FAO-56 water stress coefficients $\left(K_{s}\right)$ for comparison to modeled values (eq. 3).

In 2020 only, weekly overflights with an sUAS (Matrice 600 Pro, DJI, Shenzen, China) equipped with a thermal infrared imager, including the camera (Tau 2, Teledyne FLIR, Wilsonville, Ore.) and camera housing (ThermalCapture 2.0 640, TeAx Technology GmbH, Germany), provided thermal images of the field area with $640 \times 512$ pixel resolution and $0.04 \mathrm{~K}$ thermal resolution on 13 dates from 30 June 2020 (DOY 182) to 23 September 2020 (DOY 267). The sUAS and thermal camera were acclimated to environmental conditions for $20 \mathrm{~min}$ before flights. A flight planning application (Pix4DCapture, Pix4D SA, Lausanne, Switzerland) was used to plan flights in a grid pattern at an altitude of $50 \mathrm{~m}$ above ground level with $90 \%$ forward and lateral overlap. Flights were conducted at solar noon and required 24 min for field surveys. Thermal shutter calibration was performed throughout the flight at $0.033 \mathrm{~Hz}$, and images were captured at $1 \mathrm{~Hz}$. Prior to the field season, the thermal camera was calibrated using a black body in a thermal calibration room at the USDA facility. Thermal images of the black body were collected for combinations of nine black body temperatures and nine air temperatures within the calibration room. The calibration results were used to calibrate all thermal images collected during the growing season, and commercial photogrammetry software (Pix4Dmapper, Pix4D SA, Lausanne, Switzerland) was used for thermal image stitching and georeferencing. For each imaging date, the 5 th percentile of surface temperature within each $6 \mathrm{~m} \times 6 \mathrm{~m}$ zone (representing the coolest temperatures most likely attributed to plant canopy) was computed using the "rasterstats" package in Python. Following the graphical methodology of Idso et al. (1981), the estimates of canopy temperature were used with AZMET-measured mean air temperature and vapor pressure deficit during the overflight for post hoc analysis of crop water stress.

Cotton yield was measured via manual picking and via a commercial yield monitor on a four-row cotton picker. Two areas, each $2.0 \mathrm{~m}$ (two cotton rows) by $2.0 \mathrm{~m}$, were delineated in each plot for manual harvest. The harvest areas were located within two of the centermost $6 \mathrm{~m} \times 6 \mathrm{~m}$ zones in each plot and on rows that would not interfere with subsequent yield monitoring efforts. Following defoliation and field dry down, all mature cotton was manually picked and bagged separately within these areas, giving 48 yield samples in each growing season. Manual picking occurred on 30-31 October 2019 (DOY 303-304) and 22-23 October 2020 (DOY 296-297). Yield samples were transferred to the MAC ginning facility and weighed before separating cotton fiber, cottonseed, and trash on 18 November 2019 (DOY 322) and 30 October 2020 (DOY 304). Fiber turnout percentages were used to adjust the raw sample weights to fiber weights, and consideration of the original sampling area provided fiber yield estimates on an area basis $\left(\mathrm{kg} \mathrm{ha}^{-1}\right)$.

Following the manual harvest, site-specific yield estimates were obtained using a cotton yield monitoring system (Ag Leader, Ames, Iowa) with optical sensors installed on the two outside chutes of a four-row cotton picker on 8 November 2019 (DOY 312) and 17 November 2020 (DOY 322). Four swaths of four rows were harvested from each plot, positioned such that the two-row manual harvest areas (previously picked) passed through the center two chutes and therefore did not interfere with yield monitoring on the two outer chutes. Each $6 \mathrm{~m} \times 6 \mathrm{~m}$ zone received one pass with the yield monitoring system, providing up to 15 point-based yield estimates in each zone. The yield monitoring system consisted of a differential-correction global positioning system (DGPS), an in-cab computer display, and optical flow sensors. Standard calibration procedures were performed based on manufacturer's recommendations. The yield monitoring system provided comma-delimited data files, which were loaded into a geographic information system for visualization of spatial yield variability, intersection of data points with zones, and calculation of mean cotton yield per zone. Following comparisons to yield data from the manual harvest areas, the yield monitoring data were adjusted to improve one-to-one fit with the manual data. All further yield analysis was conducted using the yield monitor data adjusted to fit the manual measurements because the yield monitor data could better estimate yield over the entire plot area.

\section{Statistical Analysis}

Linear mixed models were computed using the "lme4" package within the R Project for Statistical Computing. The dependent variables were seasonal irrigation amount, cotton fiber yield, and water productivity, which was computed as a ratio of yield and applied irrigation. The fixed effect was the irrigation management treatment (MDL, SOL, UAS, and VRI), and the replication was fit as a random effect. Likelihood ratio tests were conducted for one model that withheld the fixed effect and another that included it, which established whether the fixed effect contributed significantly to explained variability. Tukey's multiple comparisons tests were conducted to group the treatment means.

\section{ReSULTS \\ Agronomic OUtComes}

Agronomic outcomes among treatments trended similarly in 2019 and 2020 (fig. 5). Applied irrigation was greater for the MDL and SOL treatments in both years, as compared to the UAS and VRI treatments. The MDL strategy recommended 1101 and $1088 \mathrm{~mm}$ of irrigation in 2019 and 2020, respectively. The sUAS-based $K_{c b}$ methodology employed for the UAS and VRI treatments reduced irrigation recommendations by approximately 7\% in 2019 and 14\% in 2020 . Cotton fiber yield was significantly greater in 2019 (1705 to $2312 \mathrm{~kg} \mathrm{ha}^{-1}$ ) as compared to 2020 (813 to $\left.1650 \mathrm{~kg} \mathrm{ha}^{-1}\right)$. Record-breaking heat stress conditions (fig. 2) likely limited yields in 2020 . Due to the reduced yields, water productivity was also reduced in 2020 (0.094 to $\left.0.152 \mathrm{~kg} \mathrm{~m}^{-3}\right)$ as compared to $2019\left(0.180\right.$ to $\left.0.218 \mathrm{~kg} \mathrm{~m}^{-3}\right)$. The main difference between the two growing seasons was the persistent heat stress that occurred during cotton reproductive development in 2020 . 

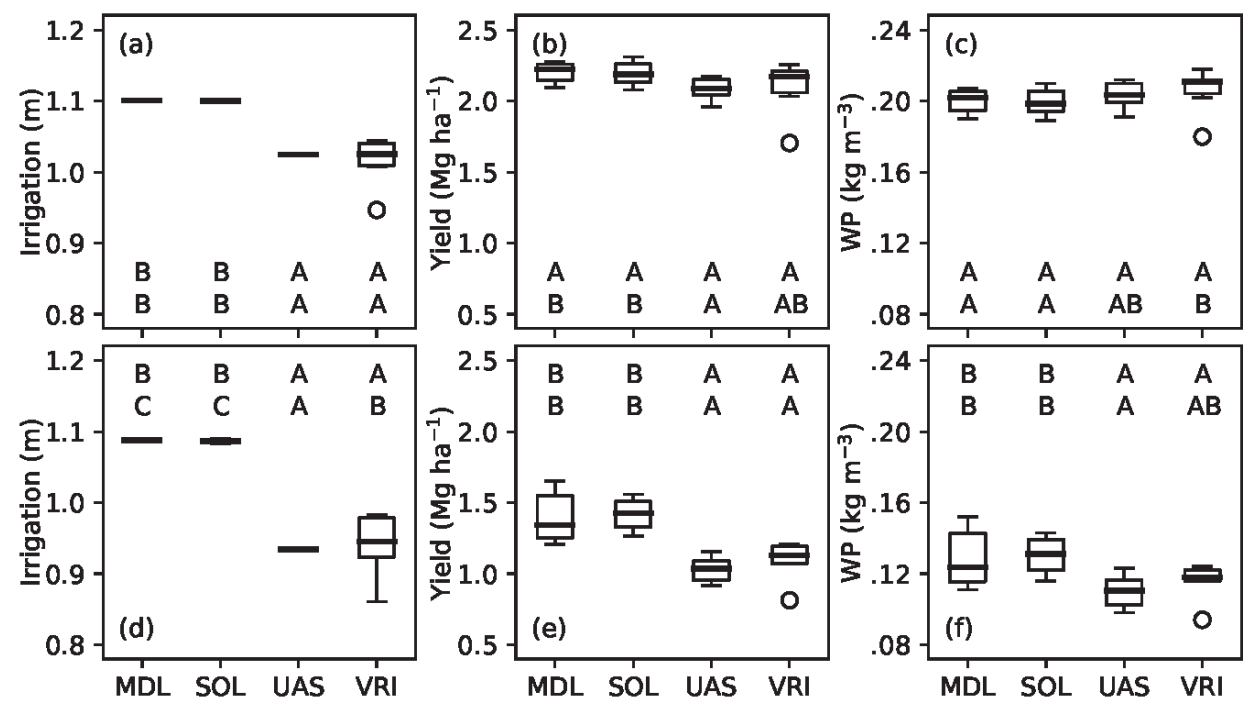

Figure 5. Agronomic outcomes for (a) seasonal applied irrigation in 2019, (b) cotton fiber yield in 2019, (c) water productivity (WP) in 2019, (d) seasonal applied irrigation in 2020, (e) cotton fiber yield in 2020, and (f) WP in 2020. Four precision irrigation management technologies with increasing complexity were tested: (1) a stand-alone FAO-56 model (MDL), (2) adding site-specific soil data (SOL), (3) adding crop coefficients $\left(K_{c b}\right)$ from an unoccupied aircraft system (UAS), and (4) adding site-specific, variable-rate irrigation applications (VRI). Capital letters represent statistical groupings among treatments with all data included (top row) and with the VRI outlier removed (bottom row).

The applied irrigation, fiber yields, and water productivities for the MDL and SOL treatments were statistically identical in both growing seasons (fig. 5). In 2019, total applied irrigation was 1101 and $1100 \mathrm{~mm}$ for the MDL and SOL treatments, respectively. Because both treatments received uniform irrigation in 2019, there was no treatment variability for irrigation applied. These results encouraged the decision to use site-specific irrigation for the SOL treatment in 2020. However, the modification did not provide a different result. In 2020, total applied irrigation for MDL was $1088 \mathrm{~mm}$, while site-specific irrigation for the SOL treatment ranged only between 1083 and $1089 \mathrm{~mm}$. Thus, evaluating site-specific soil data (fig. 1) with the FAO-56 soil water balance model did not lead to any difference in irrigation recommendations, as compared to using the field-average soil parameters. Furthermore, consideration of site-specific soil data did not lead to any change in cotton fiber yield or water productivity in the two growing seasons. The results suggest no capability for spatial soil data alone to drive agronomic improvements with site-specific irrigation management.

The UAS treatment received seasonal irrigation totals of 1025 and $935 \mathrm{~mm}$ in 2019 and 2020, respectively (fig. 5). No variation in applied irrigation was present because the UAS treatment received uniform irrigation across all plots in each season. As compared to MDL, the UAS treatment reduced applied irrigation by $76 \mathrm{~mm}(7 \%)$ in 2019 and $154 \mathrm{~mm}$ $(14 \%)$ in 2020 . Reduced irrigation recommendations were driven by an overall reduction in the sUAS-based $K_{c b}$ time series in both growing seasons, as compared to the standard trapezoidal $K_{c b}$ time series (fig. 6). This means that transpiration calculations were reduced for the UAS treatment (eq. 1), leading to reduced irrigation recommendations. As compared to the MDL treatment, irrigation reductions for the UAS treatment reduced mean cotton fiber yield from 2203 to $2086 \mathrm{~kg} \mathrm{ha}^{-1}$ (5\% loss) in 2019 and from 1397 to $1029 \mathrm{~kg} \mathrm{ha}^{-1}(26 \%$ loss) in 2020 . The yield differences were significant in 2020, but not in 2019. Likewise, mean water productivity was statistically identical between the MDL and UAS treatments in 2019, with values of 0.200 and $0.203 \mathrm{~kg} \mathrm{~m}^{-3}$, respectively. In 2020 , mean water productivity for UAS $\left(0.110 \mathrm{~kg} \mathrm{~m}^{-3}\right)$ was significantly reduced as
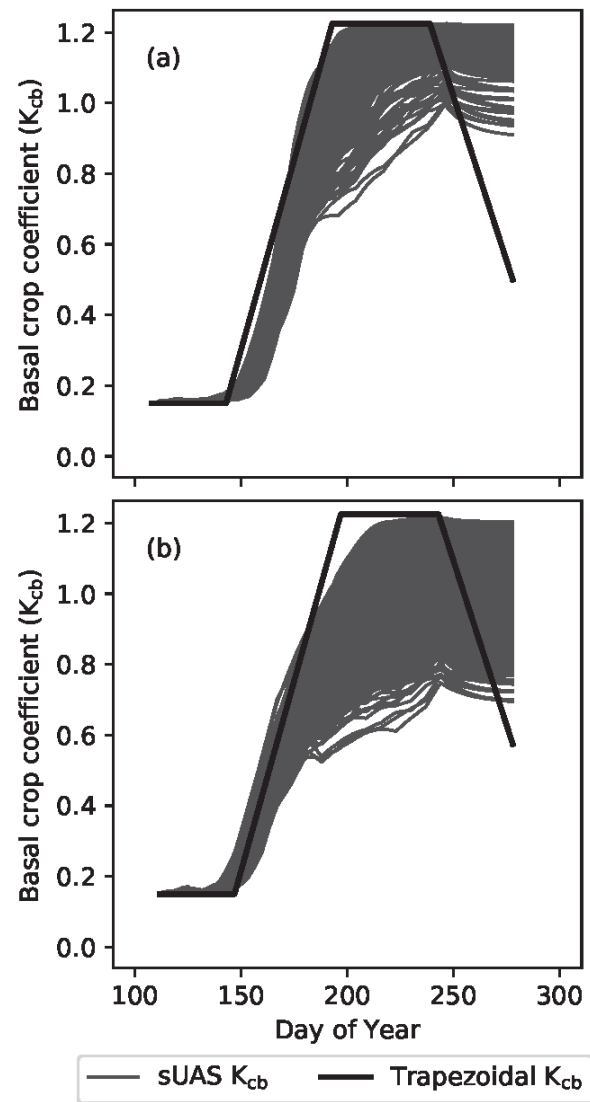

Figure 6. Basal crop coefficients $\left(K_{c b}\right)$ for the (a) 2019 and (b) 2020 cotton field studies at Maricopa, Arizona. Values were determined using: (1) FAO-56 methods for computing trapezoidal $K_{c b}$ time series and (2) estimates of fractional crop cover from small unoccupied aircraft system (sUAS) images within $6 \mathrm{~m} \times 6 \mathrm{~m}$ zones across the study area. 
compared to MDL $\left(0.129 \mathrm{~kg} \mathrm{~m}^{-3}\right)$. Possibly, the additional irrigation to MDL in 2020 assisted with cotton responses to heat stress, which was not accounted for in the modeling paradigm.

Due to site-specific irrigation management, applied irrigation amounts to the VRI treatment at the plot level were 947 to $1044 \mathrm{~mm}$ in 2019 and 861 to $983 \mathrm{~mm}$ in 2020 (fig. 5). At the level of the $6 \mathrm{~m} \times 6 \mathrm{~m}$ zones, the ranges of irrigation applied within VRI plots expanded to 887 to $1075 \mathrm{~mm}$ in 2019 and 789 to $1068 \mathrm{~mm}$ in 2020 (not shown). Thus, some zones within VRI plots received water in similar amounts to the MDL treatment, but other zones received substantially less water. In both seasons, one VRI plot provided dissimilar data (an outlier) for applied irrigation, fiber yield, and water productivity (fig. 5). The outlier was consistently located in the southernmost range (i.e., the fourth range and sixth column in 2019 and the fourth range and fourth column in 2020). The area in the southeastern portion of the field has been known for poorer productivity in past seasons due to sandier soils (fig. 1). When including the outlier in the statistical analysis, there were no yield or water productivity differences among treatments in 2019 (fig. 5); however, removing the outlier led to significantly greater water productivity for the VRI treatment $\left(0.211 \mathrm{~kg} \mathrm{~m}^{-3}\right)$ as compared to the MDL and SOL treatments (each $0.200 \mathrm{~kg} \mathrm{~m}^{-3}$ ). Regardless of outlier status, the 2019 fiber yields among the MDL, SOL, and VRI treatments were statistically identical, but the VRI treatment significantly reduced applied irrigation from 1101 to $1015 \mathrm{~mm}$ (an $8 \%$ reduction) as compared to MDL. Importantly, the VRI treatment was able to maintain yield while reducing water applied in 2019, regardless of outlier status. In 2020, including the outlier led to significantly greater water productivity for MDL $\left(0.129 \mathrm{~kg} \mathrm{~m}^{-3}\right)$ as compared to the VRI treatment $\left(0.116 \mathrm{~kg} \mathrm{~m}^{-3}\right)$. However, when removing the outlier, the water productivities for the MDL and VRI treatments were not significantly different. Furthermore, in comparing the UAS and VRI treatments, the mean fiber yields and water productivities were greater for VRI in both growing seasons, although none of these differences were significant regardless of outlier status. The results provided important field verification that site-specific irrigation management can lead to improvements in water productivity, although the measured improvements in this study were minor and likely limited by imperfections in the irrigation scheduling paradigm.

\section{CROP COEFFICIENT ESTIMATION}

Experimental outcomes were driven by differences in $K_{c b}$ estimation (fig. 6), which led to differences in irrigation recommendations (figs. 5a and 5d) and cotton fiber yield (figs. 5b and 5e) among treatments that used the standard trapezoidal $K_{c b}$ (MDL and SOL) and the sUAS-based $K_{c b}$ (UAS and VRI). In 2019, reductions in sUAS-based $K_{c b}$ were initially driven by cooler air temperatures in the early season through the end of May (DOY 151, fig. 2), which delayed plant growth and reduced early-season $f_{c}$. This caused the sUAS-based $K_{c b}$ curves to lag the standard trapezoidal curve until late June (fig. 6a). In 2020, the early-season sUAS-based $K_{c b}$ curves more closely matched the standard $K_{c b}$ trapezoid (fig. 6b). With heat stress beginning in July each year (fig. 2), plant growth rates slowed, leading to reduced $K_{c b}$ from sUAS-based $f_{c}$ as compared to the standard trapezoid (fig. 6). As compared to 2019, the greater heat stress in 2020 (fig. 2) led to greater $K_{c b}$ reductions in 2020 (fig. 6). Overall, these reductions in $K_{c b}$ from the sUAS approach led to reduced applied irrigation and drove the differences in yield. The estimation of $K_{c b}$ via $f_{c}$ is not flawed, as FAO-56 suggests that $K_{c b}$ can be estimated from $f_{c}$ and vice versa (Allen et al., 1998). However, the sUAS-based $K_{c b}$ methodology clearly lacked capability to identify stress and lead the model toward management practices to reduce stress. Further investigation of the $K_{s}$ term (eq. 1) was therefore needed to examine these limitations.

Because the field was typically irrigated on Thursdays and Fridays, the simulated $K_{s}$ data were evaluated by day of the week from Friday to the following Thursday from early June (DOY 151 in 2019 and DOY 150 in 2020) through early September (DOY 248 in 2019 and DOY 247 in 2020) in each year (table 2). The reported $K_{s}$ data are not forecasted values but were calculated post hoc with actual weather information and irrigation schedules. Furthermore, due to the structure of the daily timestep model, the $K_{s}$ data represent conditions at the beginning of the day of week. No water stress (i.e., $K_{s}=1$ ) was simulated on Fridays, Saturdays, Sundays, or Mondays for any $6 \mathrm{~m} \times 6 \mathrm{~m}$ zone and for any irrigation treatment in both years. In addition, except for a

Table 2. Summary of the water stress coefficients $\left(K_{s}\right)$ as simulated post hoc by the FAO-56 soil water balance model among 6 m $\times 6$ m zones for each of four irrigation scheduling treatments (MDL, SOL, UAS, and VRI) in a two-year cotton field study at Maricopa, Arizona. The $K_{s}$ data were summarized by day of week from early June through early September in each year. Metrics include the percentage of occurrences of $K_{s}=1$ $\left(\% K_{s}=1\right)$, meaning no water stress, and the minimum simulated $K_{s}$ value (Min $\left.K_{s}\right)$.

\begin{tabular}{|c|c|c|c|c|c|c|c|c|c|}
\hline \multirow[b]{2}{*}{ Year } & \multirow[b]{2}{*}{ Day of Week } & \multicolumn{2}{|c|}{ MDL } & \multicolumn{2}{|c|}{ SOL } & \multicolumn{2}{|c|}{ UAS } & \multicolumn{2}{|c|}{ VRI } \\
\hline & & $\% K_{s}=1$ & $\operatorname{Min} K_{s}$ & $\% K_{s}=1$ & $\operatorname{Min} K_{s}$ & $\% K_{s}=1$ & $\operatorname{Min} K_{s}$ & $\% K_{s}=1$ & $\operatorname{Min} K_{s}$ \\
\hline \multirow[t]{7}{*}{2019} & Fridays & $100 \%$ & 1.00 & $100 \%$ & 1.00 & $100 \%$ & 1.00 & $100 \%$ & 1.00 \\
\hline & Saturdays & $100 \%$ & 1.00 & $100 \%$ & 1.00 & $100 \%$ & 1.00 & $100 \%$ & 1.00 \\
\hline & Sundays & $100 \%$ & 1.00 & $100 \%$ & 1.00 & $100 \%$ & 1.00 & $100 \%$ & 1.00 \\
\hline & Mondays & $100 \%$ & 1.00 & $100 \%$ & 1.00 & $100 \%$ & 1.00 & $100 \%$ & 1.00 \\
\hline & Tuesdays & $100 \%$ & 1.00 & $100 \%$ & 1.00 & $93 \%$ & 0.97 & $100 \%$ & 1.00 \\
\hline & Wednesdays & $93 \%$ & 0.99 & $93 \%$ & 0.99 & $86 \%$ & 0.94 & $100 \%$ & 1.00 \\
\hline & Thursdays & $79 \%$ & 0.83 & $79 \%$ & 0.83 & $64 \%$ & 0.79 & $93 \%$ & 0.89 \\
\hline \multirow[t]{7}{*}{2020} & Fridays & $100 \%$ & 1.00 & $100 \%$ & 1.00 & $100 \%$ & 1.00 & $100 \%$ & 1.00 \\
\hline & Saturdays & $100 \%$ & 1.00 & $100 \%$ & 1.00 & $100 \%$ & 1.00 & $100 \%$ & 1.00 \\
\hline & Sundays & $100 \%$ & 1.00 & $100 \%$ & 1.00 & $100 \%$ & 1.00 & $100 \%$ & 1.00 \\
\hline & Mondays & $100 \%$ & 1.00 & $100 \%$ & 1.00 & $100 \%$ & 1.00 & $100 \%$ & 1.00 \\
\hline & Tuesdays & $100 \%$ & 1.00 & $100 \%$ & 1.00 & $100 \%$ & 1.00 & $100 \%$ & 1.00 \\
\hline & Wednesdays & $86 \%$ & 0.97 & $86 \%$ & 0.97 & $100 \%$ & 1.00 & $100 \%$ & 1.00 \\
\hline & Thursdays & $57 \%$ & 0.78 & $57 \%$ & 0.78 & $86 \%$ & 0.86 & $100 \%$ & 1.00 \\
\hline
\end{tabular}


few cases in the UAS treatment in 2019, no water stress was simulated on Tuesdays. Minimal water stress with $K_{s}$ values no less than 0.94 was simulated in a small fraction of cases (i.e., zones and weeks) on Wednesdays. On Thursdays, immediately prior to weekly irrigation events, the model simulated water stress with $K_{s}$ values no less than 0.78 and occurring in less than half to less than a quarter of cases depending on the treatment. The simulated water stress perhaps resulted from actual water use being greater than forecasted water use at the time of irrigation scheduling or perhaps from practical matters limiting irrigation application as compared to the calculated requirement. In any case, the modeled $K_{s}$ data indicate that a substantial portion of the field remained free of water stress most of the time. Theoretically, this means that irrigation management proceeded efficiently without overwatering, and minimal stress was occasionally present just prior to Thursday irrigation events. However, the amounts of simulated water stress among treatments generally did not explain the trends in yield (fig. 5). For example, while greater yield was measured for the MDL treatment, the VRI treatment was simulated with the least overall water stress (table 2).

Computations of $K_{s}$ from measured soil water content data generally agreed with modeled $K_{s}$ from the FAO-56 model $\left(K_{s}\right.$ calculations from soil water content measurements were based on the rooting depth simulated by the model on the soil water content measurement date). However, soil water content was measured primarily on Mondays and occasionally on Tuesdays, when no water stress was simulated (table 2). In 2019, no water stress $\left(K_{s}=1\right)$ was computed from measured soil water content on any measurement date from 13 May 2019 (DOY 133) to 16 September 2019 (DOY 259). In 2020, except for one plot (plot 24), no water stress $\left(K_{s}=1\right)$ was computed from measured soil water content on any measurement date from 4 May 2020 (DOY 125) to 14 September 2020 (DOY 258). Soil water content data from the excepted plot in 2020 was consistently and substantially less than that from all other plots, perhaps indicating an issue with improper access tube installation. Overall, neither the $K_{s}$ calculations by FAO-56 (table 2) nor $K_{s}$ from root zone soil water content data (not shown) could identify water stress as a reason for reduced yield with the UAS and VRI treatments (fig. 5). Possibly, these failures could be related to the sensitivity of $K_{s}$ calculations to rooting depth assumptions, which are highly uncertain. A maximum rooting depth of $1.4 \mathrm{~m}$ was assumed throughout this study. If the actual maximum rooting depth was less than $1.4 \mathrm{~m}$, less water would be available for use by the crop, which would enable more rapid onset of water stress than predicted, possibly leading to the observed differences in yield.

\section{THERMAL IMAGING}

Contrary to the $K_{S}$ computations, the 2020 thermal imaging data clearly identified greater water stress in the UAS and VRI treatments as compared to the MDL and SOL treatments (fig. 7). Thermal overflights were conducted primarily on Tuesday afternoons and occasionally on Wednesday, when the FAO-56 model simulated little to no water stress effects (table 2). However, on all thermal imaging dates from 7 July 2020 (DOY 189) to 23 September 2020 (DOY 267),
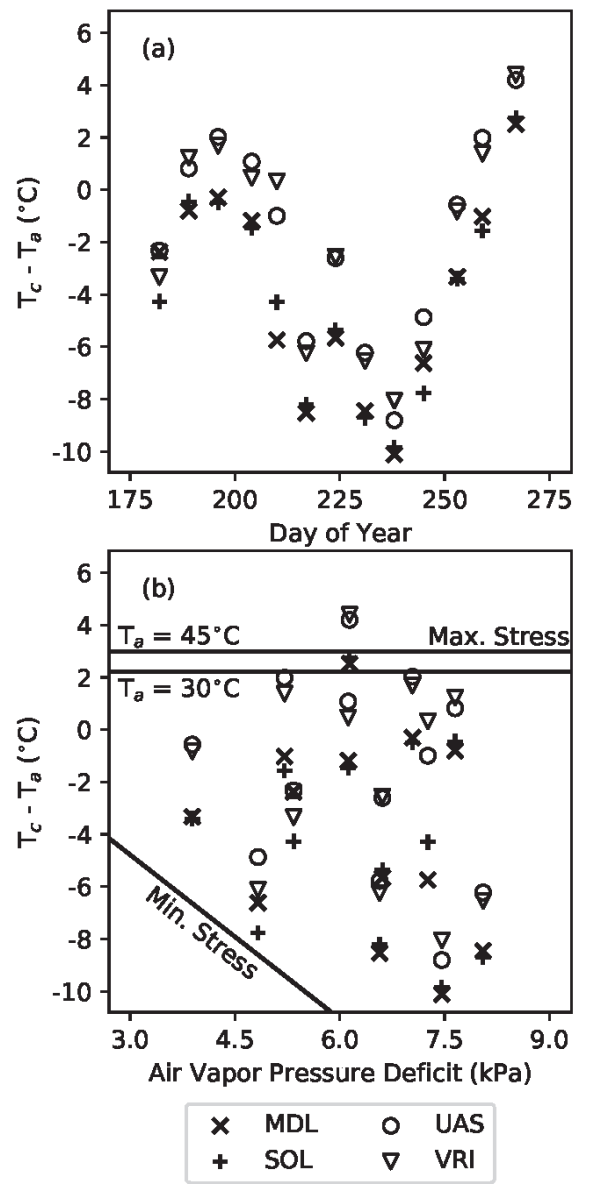

Figure 7. Mean responses of cotton canopy temperature $\left(T_{c}\right)$ minus air temperature ( $\left.T_{a}\right)$ versus (a) day of year and (b) air vapor pressure deficit among four irrigation management treatments (MDL, SOL, UAS, and VRI) at Maricopa, Arizona, in 2020. The lower plot follows the methodologies of Idso et al. (1981) and Idso (1982) to establish limits for cotton water stress.

canopy minus air temperatures were on average $2.2^{\circ} \mathrm{C}$ cooler for the MDL and SOL treatments as compared to the UAS and VRI treatments (fig. 7a). This means that the additional irrigation applied to the MDL and SOL treatments (fig. 5d) provided water for greater evaporative cooling and stress reduction, which led to higher yield for MDL and SOL as compared to UAS and VRI in 2020 (fig. 5e). Following the methodology of Idso et al. (1981), canopy and air temperature differences were plotted against air vapor pressure deficit to establish the limits for cotton water stress (fig. 7b). Idso (1982) provided the equation for the minimum water stress baseline for cotton based on data from Phoenix, Arizona: $y=1.49-2.09 x$. Maximum water stress lines were computed for air temperatures of $30^{\circ} \mathrm{C}$ and $45^{\circ} \mathrm{C}$, which spanned the range of conditions for thermal data collection in this study. The data clearly indicate that variable levels of water stress were present among treatments at the times of thermal infrared data collection and that the MDL and SOL treatments experienced less water stress than the UAS and VRI treatments. Furthermore, the crop water stress methodology of Idso et al. (1981) demonstrated greater sensitivity for the identification of water stress among treatments as compared to $K_{s}$ computations (eq. 3 ) from either measured or modeled 
soil water status (table 2). In the future, thermal infrared data and crop water stress analysis could possibly be used to adjust the rooting depth assumption required for $K_{s}$ computations (eqs. 2 and 3), which could make $K_{s}$ values more representative of actual water stress conditions.

\section{DISCUSSION}

This study provided ample guidance on the strengths and weaknesses of various technologies used to inform precision irrigation management decisions, particularly related to the ability of different technologies to result in favorable agronomic outcomes. The following discussion aims to elucidate the strengths and weaknesses of the various technologies contrasted herein and provide a vision for the future use of these technologies for precision irrigation management.

Maps of soil water holding properties alone were inadequate for improving agronomic outcomes through site-specific water balance modeling and site-specific irrigation application. Quite simply, there were no differences in agronomic outcomes between the MDL and SOL treatments. An explanation may be related to the spatial correlation between DUL and LL across the field, which had similar spatial trends (fig. 1). Thus, the total available water (TAW, eq. 2), which forms the backbone of many soil water balance models, exhibited more uniformity than evident from the DUL and LL maps. Nonetheless, plant growth variation was often qualitatively (through human observation) and quantitatively (fig. 3d) related to the spatial DUL and LL patterns in the field. However, use of spatial TAW alone within the modeling paradigm was unable to recommend meaningful differences in irrigation management decisions to account for this variation. The model likely failed to consider a biological response to spatial variability in DUL or LL, such as variable rooting depth and effects of root growth on soil hydraulic properties (Lu et al., 2020). The result has implications for several past modeling studies that used spatial soil water holding properties alone to evaluate potential for sitespecific irrigation management to improve yield, net return, or water productivity (Nijbroek et al., 2003; Thorp, 2020). Such studies have reported little to no benefit for site-specific irrigation management to improve agronomic outcomes, but basing the analysis on soil variability alone may not fully explain the potential benefit. This study showed that near-real-time crop feedbacks from sUAS imaging offered more for determining site-specific irrigation management than variation in soil water holding properties alone, particularly the ability of sUAS to map meaningful differences in crop cover and crop water stress throughout the growing season.

Related to the previous point, soil water balance models alone were also inadequate for informing site-specific irrigation decisions. There was no advantage to the SOL treatment in this study, where the model was applied site-specifically but without any in-season feedbacks on crop or soil status. The results showed that relatively favorable agronomic outcomes could be achieved with the simple MDL strategy, where the model was applied in a traditional, non-spatial way using field-average soil data and default trapezoidal crop coefficient data. However, this modeling methodology is now decades old and offers little novelty toward the advancement of technology for precision irrigation management. Furthermore, the default trapezoidal $K_{c b}$ data diverged substantially from sUAS-based $K_{c b}$ estimates (fig. 6), and the stress coefficients calculated by the model $\left(K_{s}\right.$, table 2$)$ failed to explain differences in canopy temperature or fiber yield among treatments. Although the MDL treatment led to favorable agronomic outcomes, the results suggest that the modeling paradigm has limitations and that improvements to the methodology are needed. With modern advancements in the collection of abundant, near-real-time crop and soil data during the growing season, a likely solution is to further improve the methodologies for integration of data with models. However, the methodologies for such integrations are not well developed and depend heavily on the types of available data and sensitivities of the model. While models are important for providing mechanistic meaning, filling gaps between observations, and predicting the future, further efforts are necessary to effectively use data from modern sensing systems to drive models toward defensible management decisions that achieve desired agronomic outcomes. This goal is relevant whether the model is used site-specifically or not, although modern imaging technologies certainly facilitate spatial applications of models.

Fractional crop cover estimates alone were inadequate for informing site-specific irrigation recommendations. In this study, the UAS treatment tested a methodology for specifying $K_{c b}$ from site-specific fractional cover estimates. However, compared to using default trapezoidal $K_{c b}$ with the MDL treatment, the agronomic outcomes from the UAS treatment were less favorable in both growing seasons. Clearly, the factors leading to reduced yield in the UAS treatment were not under consideration in the data processing pipeline and modeling framework that produced its irrigation schedule. Therefore, additional data and model adjustments beyond updating $K_{c b}$ were likely needed to make the simulations more realistic and provide improved irrigation recommendations. For example, the model's rooting depth computations were scaled based on $K_{c b}$ inputs with the maximum rooting depth $(1.4 \mathrm{~m})$ corresponding to maximum $K_{c b}$ (1.225). Within the model framework, rooting depth impacted daily root-zone TAW (eq. 2 ) as well as $K_{s}$ calculations (eq. 3). However, rooting depth is difficult to measure and highly uncertain, which likely impacted the model predictions of water stress and the irrigation recommendations. Perhaps the maximum rooting depth should be spatially variable within the modeling framework, and modeled rooting depth could be informed by water stress estimates from canopy temperature. While measurements of canopy temperature and soil water content were not incorporated into the irrigation scheduling paradigm in this study, the results suggest opportunities for using such data to further update and improve irrigation recommendations from the model, because canopy temperature data differentiated water stress among treatments and soil water content data can provide checks on the model's soil water balance in obvious ways. Future research is needed to formulate strategies for integration of such data with the model, similar to the strategy developed herein for obtaining $K_{c b}$ from UAS-based fractional 
cover (figs. 3 and 4). Development of the $K_{c b}$ data pipeline in this study was the most positive outcome of the UAS treatment, and further research should develop similar techniques for updating modeled $K_{s}$ and/or rooting depth.

Site-specific irrigation management with the VRI treatment led to minor improvements in water productivity in 2019 by maintaining fiber yield with reduced irrigation applied; however, site-specific irrigation management did not lead to better agronomic outcomes as compared to uniform management in 2020. The findings agreed with other field studies, which concluded that site-specific irrigation management offered minimal benefit as compared to uniform management and that improvements likely did not justify the cost of the site-specific irrigation equipment (Evans and King, 2012; Evans et al., 2013; King et al., 2006; Sadler et al., 2002b; Stone et al., 2015). However, different results may be found in other regions where greater rainfall amounts and topographic variability can lead to spatial variability in soil water contents. The limitations of the modeling paradigm used for irrigation scheduling, as discussed above, was likely the primary reason for the mediocre performance of the VRI treatment, because plant growth variability, as assessed by regular human observation throughout the growing season, certainly existed even across this relatively small ( $2.8 \mathrm{ha}$ ) cotton field. Lacking are integrated data collection platforms and algorithms for accurately quantifying field variability and recommending irrigation schedules that lead to meaningful and predictable improvements in agronomic outcomes. Future efforts should focus on such developments, which are important regardless of whether irrigation is applied spatially or uniformly.

A main limitation of all the irrigation scheduling methods tested herein was that they only considered near-term soil water balance calculations to compute irrigation recommendations (eq. 4). However, soil water status is certainly not the agronomic outcome of greatest interest; likely yield is. Increasingly, water savings by reducing irrigation is also an important outcome due to limitations in water availability. For cotton production, boll retention and internode stem length (as an indicator of rankness) are also important, and both are impacted by water management. Environmental outcomes, such as losses of nutrients, pesticides, and sediment from crop fields, are also often important, and soil salinity management is important in some areas. None of the methods evaluated in this study considered the effects of water management on these other important outcomes. Future irrigation management tools must therefore consider how water management will affect the specific agronomic or environmental outcomes of interest (e.g., maximizing yield given a specific water availability limitation rather than maintaining near-term soil water depletion below a threshold). In this way, the tools will have greater relevance regarding the specific objectives and constraints of field management, and following their recommendations may more naturally lead to the real outcomes the tools were designed to provide. Comprehensive agroecosystem models may provide utility toward this goal (Cheviron et al., 2016; Thorp et al., 2017); however, model updating using data from modern data collection systems will still be required to keep models true to real field conditions.

\section{Conclusions}

Overall, this study revealed many insights on the ability of different precision irrigation management technologies to influence agronomic outcomes for Arizona cotton. First, use of site-specific soil data alone offered no improvement to agronomic outcomes as compared to using field-average soil data within the modeling paradigm. Second, a data pipeline was successful for estimating basal crop coefficients from sUAS-based fractional crop cover; however, yield reductions from the approach, as compared to that from standard trapezoidal crop coefficient data, suggested that additional data and techniques were necessary to identify crop water stress. Third, site-specific irrigation offered minor benefits in one of the two growing seasons by reducing irrigation applied while maintaining yield as compared to conventional uniform irrigation. Finally, post hoc data analysis demonstrated opportunities for soil water content data and sUASbased thermal imaging to identify crop water stress and further improve the modeling paradigm for precision irrigation management.

Taken together, this study suggested two objectives for advancing precision irrigation management in the future: (1) development of algorithms and models that better predict real field conditions, that better accept data inputs from modern data collection systems, and that better consider the agronomic or environmental outcomes of greatest interest; and (2) development of data pipelines and methodologies for integrating sensor data with models to ensure that recommendations are based on accurate representations of field conditions. Overall, integration of data with models is the key for success, but research must identify the specific methodologies that lead sensing and modeling tools toward recommendations that achieve intended outcomes. Regarding site-specific management of irrigation, this study, like many others, identified only occasional and minor improvements in water productivity from this technology. The findings suggest that irrigation scheduling algorithms and sensor data integration pipelines should be prioritized, which will be relevant whether irrigation applications are uniform or spatially variable. With improved data inputs and modeling paradigms, future field studies may demonstrate more substantial advantages for site-specific irrigation management.

\section{ACKNOWLEDGEMENTS}

The authors acknowledge Cotton Incorporated (Project Nos. 17-642, 18-384, 20-720, and 21-830), Yuma Center of Excellence Small Grants Program Project (No. 2019-04), and University of Arizona startup funds for contributing partial funding for this research. In addition, the authors acknowledge the technicians, post-docs, and students at Maricopa who helped conduct field experiments, collect field data, and complete harvest and ginning activities: Matt Hagler, Suzette Maneely, Lianne Evans, Sharette Rockholt, Kathy Johnson, Melissa Stefanek, Patrick Ashe, Joe Griffin, Matthew Herritt, Bruno Rozzi, Ace Pugh, Emmanuel Gonzalez, and Giovanni Melandri. Alanna Zubler is acknowledged for creating the Python script to relate GCP coordinates to sUAS image coordinates for georeferencing purposes. Karen Geldmacher and Americot are acknowledged 
for providing the cotton seed. Pedro Andrade-Sanchez and John Heun are acknowledged for providing spatial yield data from the cotton yield monitor. Finally, Andrew French and Jeffrey Demieville are acknowledged for conducting the calibration of the thermal imager.

\section{REFERENCES}

Alchanatis, V., Cohen, Y., Cohen, S., Moller, M., Sprinstin, M., Meron, M., ... Sela, E. (2010). Evaluation of different approaches for estimating and mapping crop water status in cotton with thermal imaging. Prec. Agric., 11(1), 27-41. https://doi.org/10.1007/s11119-009-9111-7

Allen, R. G., Pereira, L. S., Raes, D., \& Smith, M. (1998). Crop evapotranspiration: Guidelines for computing crop water requirements. FAO Irrigation and Drainage Paper No. 56. Rome, Italy: United Nations FAO.

Andrade, M. A., O'Shaughnessy, S. A., \& Evett, S. R. (2020a). ARSpivot, a sensor-based decision support software for variable-rate irrigation center pivot systems: Part A. Development. Trans. ASABE, 63(5), 1521-1533. https://doi.org/10.13031/trans.13907

Andrade, M. A., O'Shaughnessy, S. A., \& Evett, S. R. (2020b). ARSPivot, a sensor-based decision support software for variable-rate irrigation center pivot systems: Part B. Application. Trans. ASABE, 63(5), 1535-1547. https://doi.org/10.13031/trans.13908

Barker, J. B., Franz, T. E., Heeren, D. M., Neale, C. M., \& Luck, J. D. (2017). Soil water content monitoring for irrigation management: A geostatistical analysis. Agric. Water Mgmt., 188, 36-49. https://doi.org/10.1016/j.agwat.2017.03.024

Barker, J. B., Heeren, D. M., Neale, C. M., \& Rudnick, D. R. (2018). Evaluation of variable-rate irrigation using a remotesensing-based model. Agric. Water Mgmt., 203, 63-74. https://doi.org/10.1016/j.agwat.2018.02.022

Bhatti, S., Heeren, D. M., Barker, J. B., Neale, C. M., Woldt, W. E., Maguire, M. S., \& Rudnick, D. R. (2020). Site-specific irrigation management in a sub-humid climate using a spatial evapotranspiration model with satellite and airborne imagery. Agric. Water Mgmt., 230, 105950. https://doi.org/10.1016/j.agwat.2019.105950

Bian, J., Zhang, Z., Chen, J., Chen, H., Cui, C., Li, X., ... Fu, Q. (2019). Simplified evaluation of cotton water stress using highresolution unmanned aerial vehicle thermal imagery. Remote Sensing, 11(3), 267. https://doi.org/10.3390/rs11030267

Booker, J. D., Lascano, R. J., Molling, C. C., Zartman, R. E., \& Acosta-Martinez, V. (2015). Temporal and spatial simulation of production-scale irrigated cotton systems. Prec. Agric., 16(6), 630-653. https://doi.org/10.1007/s11119-015-9397-6

Bronson, K. F. (2021). Optimal internal nitrogen use efficiency for irrigated cotton in the southwestern United States. Agron. J., 113(3), 2821-2831. https://doi.org/10.1002/agj2.20674

Brown, P. W. (2008). Cotton heat stress. Tech. Rep. AZ1448. Tucson, AZ: University of Arizona, College of Agriculture and Life Science, Cooperative Extension.

Cheviron, B., Vervoort, R. W., Albasha, R., Dairon, R., Le Priol, C., \& Mailhol, J.-C. (2016). A framework to use crop models for multi-objective constrained optimization of irrigation strategies. Environ. Model. Software, 86, 145-157. https://doi.org/10.1016/j.envsoft.2016.09.001

De Lara, A., Khosla, R., \& Longchamps, L. (2018). Characterizing spatial variability in soil water content for precision irrigation management. Agron. J., 8(5), article 59. https://doi.org/10.3390/agronomy 8050059
Evans, R. G., \& King, B. A. (2012). Site-specific sprinkler irrigation in a water-limited future. Trans. ASABE, 55(2), 493-504. https://doi.org/10.13031/2013.41382

Evans, R. G., Iversen, W. M., \& Kim, Y. (2012). Integrated decision support, sensor networks, and adaptive control for wireless site-specific sprinkler irrigation. Appl. Eng. Agric., 28(3), 377-387. https://doi.org/10.13031/2013.41480

Evans, R. G., LaRue, J., Stone, K. C., \& King, B. A. (2013). Adoption of site-specific variable-rate sprinkler irrigation systems. Irrig. Sci., 31(4), 871-887. https://doi.org/10.1007/s00271-012-0365-x

Evett, S. R., O’Shaughnessy, S. A., Andrade, M. A., Colaizzi, P. D., Schwartz, R. C., Schomberg, H. S., ... Sui, R. (2020a). Theory and development of a VRI decision support system: The USDAARS ISSCADA approach. Trans. ASABE, 63(5), 1507-1519. https://doi.org/10.13031/trans.13922

Evett, S. R., O'Shaughnessy, S. A., Andrade, M. A., Kustas, W. P., Anderson, M. C., Schomberg, H. S., \& Thompson, A. (2020b). Precision agriculture and irrigation: Current U.S. perspectives. Trans. ASABE, 63(1), 57-67. https://doi.org/10.13031/trans.13355

Falkenberg, N. R., Piccinni, G., Cothren, J. T., Leskovar, D. I., \& Rush, C. M. (2007). Remote sensing of biotic and abiotic stress for irrigation management of cotton. Agric. Water Mgmt., 87(1), 23-31. https://doi.org/10.1016/j.agwat.2006.05.021

French, A. N., Hunsaker, D. J., \& Thorp, K. R. (2015). Remote sensing of evapotranspiration over cotton using the TSEB and METRIC energy balance models. Remote Sensing Environ., 158, 281-294. https://doi.org/10.1016/j.rse.2014.11.003

Gee, G. W., \& Bauder, J. W. (1986). Particle-size analysis. In A. Klute (Ed.), Methods of soil analysis: Part 1. Physical and mineralogical methods (2nd Ed., pp. 383-411). Madison, WI: ASA, SSSA. https://doi.org/10.2136/sssabookser5.1.2ed.c15

González Perea, R., Daccache, A., Rodríguez Díaz, J. A., Camacho Poyato, E., \& Knox, J. W. (2018). Modeling impacts of precision irrigation on crop yield and in-field water management. Prec. Agric., 19(3), 497-512. https://doi.org/10.1007/s11119-017-9535-4

Haghverdi, A., Leib, B. G., Washington-Allen, R. A., Buschermohle, M. J., \& Ayers, P. D. (2016). Studying uniform and variable-rate center pivot irrigation strategies with the aid of site-specific water production functions. Comput. Electron. Agric., 123, 327-340. https://doi.org/10.1016/j.compag.2016.03.010

Hedley, C. B., \& Yule, I. J. (2009a). A method for spatial prediction of daily soil water status for precise irrigation scheduling. Agric. Water Mgmt., 96(12), 1737-1745. https://doi.org/10.1016/j.agwat.2009.07.009

Hedley, C. B., \& Yule, I. J. (2009b). Soil water status mapping and two variable-rate irrigation scenarios. Prec. Agric., 10(4), 342355. https://doi.org/10.1007/s11119-009-9119-z

Hunsaker, D. J., Barnes, E. M., Clarke, T. R., Fitzgerald, G. J., \& Pinter Jr, P. J. (2005). Cotton irrigation scheduling using remotely sensed and FAO-56 basal crop coefficients. Trans. ASAE, 48(4), 1395-1407. https://doi.org/10.13031/2013.19197

Hunsaker, D. J., French, A. N., Waller, P. M., Bautista, E., Thorp, K. R., Bronson, K. F., \& Andrade-Sanchez, P. (2015). Comparison of traditional and ET-based irrigation scheduling of surface-irrigated cotton in the arid southwestern USA. Agric. Water Mgmt., 159, 209-224. https://doi.org/10.1016/j.agwat.2015.06.016

Idso, S. B. (1982). Non-water-stressed baselines: A key to measuring and interpreting plant water stress. Agric. Meteorol., 27(1), 59-70. https://doi.org/10.1016/0002-1571(82)90020-6

Idso, S. B., Jackson, R. D., Pinter, P. J., Reginato, R. J., \& Hatfield, J. L. (1981). Normalizing the stress-degree-day parameter for 
environmental variability. Agric. Meteorol., 24, 45-55. https://doi.org/10.1016/0002-1571(81)90032-7

Kelley, J., McCauley, D., Alexander, G. A., Gray IV, W. F., Siegfried, R., \& Oldroyd, H. J. (2020). Using machine learning to integrate on-farm sensors and agro-meteorology networks into site-specific decision support. Trans. ASABE, 63(5), 1427-1439. https://doi.org/10.13031/trans.13917

King, B. A., Stark, J. C., \& Wall, R. W. (2006). Comparison of sitespecific and conventional uniform irrigation management for potatoes. Appl. Eng. Agric., 22(5), 677-688. https://doi.org/10.13031/2013.22000

Kranz, W. L., Evans, R. G., Lamm, F. R., O’Shaughnessy, S. A., \& Peters, R. T. (2012). A review of mechanical-move sprinkler irrigation control and automation technologies. Appl. Eng. Agric., 28(3), 389-397. https://doi.org/10.13031/2013.41494

Lo, T. H., Heeren, D. M., Martin, D. L., Mateos, L., Luck, J. D., \& Eisenhauer, D. E. (2016). Pumpage reduction by using variablerate irrigation to mine undepleted soil water. Trans. $A S A B E$, 59(5), 1285-1298. https://doi.org/10.13031/trans.59.11773

Lo, T. H., Heeren, D. M., Mateos, L., Luck, J. D., Martin, D. L., Miller, K. A., ... Shaver, T. M. (2017). Field characterization of field capacity and root zone available water capacity for variable-rate irrigation. Appl. Eng. Agric., 33(4), 559-572. https://doi.org/10.13031/aea.11963

Lu, J., Zhang, Q., Werner, A. D., Li, Y., Jiang, S., \& Tan, Z. (2020). Root-induced changes of soil hydraulic properties: A review. $J$. Hydrol., 589, article 125203. https://doi.org/10.1016/j.jhydrol.2020.125203

McCarthy, A. C., Hancock, N. H., \& Raine, S. R. (2013). Advanced process control of irrigation: The current state and an analysis to aid future development. Irrig. Sci., 31(3), 183-192. https://doi.org/10.1007/s00271-011-0313-1

Migliaccio, K. W., Morgan, K. T., Vellidis, G., Zotarelli, L., Fraisse, C., Zurweller, B. A., ... Rowland, D. L. (2016). Smartphone apps for irrigation scheduling. Trans. ASABE, 59(1), 291-301. https://doi.org/10.13031/trans.59.11158

Neupane, J., \& Guo, W. (2019). Agronomic basis and strategies for precision water management: A review. Agronomy, 9(2), article 87. https://doi.org/10.3390/agronomy9020087

Nijbroek, R., Hoogenboom, G., \& Jones, J. W. (2003). Optimizing irrigation management for a spatially variable soybean field. Agric. Syst., 76(1), 359-377. https://doi.org/10.1016/S0308521X(02)00127-0

O’Shaughnessy, S. A., Evett, S. R., \& Colaizzi, P. D. (2015). Dynamic prescription maps for site-specific variable-rate irrigation of cotton. Agric. Water Mgmt., 159, 123-138. https://doi.org/10.1016/j.agwat.2015.06.001

O’Shaughnessy, S. A., Evett, S. R., Colaizzi, P. D., \& Howell, T. A. (2011). Using radiation thermography and thermometry to evaluate crop water stress in soybean and cotton. Agric. Water Mgmt., 98(10), 1523-1535. https://doi.org/10.1016/j.agwat.2011.05.005

O'Shaughnessy, S. A., Evett, S. R., Colaizzi, P. D., Andrade, M. A., Marek, T. H., Heeren, D. M., ... LaRue, J. L. (2019). Identifying advantages and disadvantages of variable-rate irrigation: An updated review. Appl. Eng. Agric., 35(6), 837-852. https://doi.org/10.13031/aea.13128

Peters, R. T., \& Evett, S. R. (2007). Spatial and temporal analysis of crop conditions using multiple canopy temperature maps created with center-pivot-mounted infrared thermometers. Trans. ASABE, 50(3), 919-927. https://doi.org/10.13031/2013.23156

Rudnick, D. R., \& Irmak, S. (2014). Spatial and temporal maize soil water extraction (depletion) dynamics: Part I. Development and evaluation of a soil water extraction model. Trans. ASABE, 57(2), 431-444. https://doi.org/10.13031/trans.57.10253
Sadler, E. J., Camp, C. R., Evans, D. E., \& Millen, J. A. (2002a). Corn canopy temperatures measured with a moving infrared thermometer array. Trans. ASAE, 45(3), 581-591. https://doi.org/10.13031/2013.8855

Sadler, E. J., Camp, C. R., Evans, D. E., \& Millen, J. A. (2002b). Spatial variation of corn response to irrigation. Trans. ASAE, 45(6), 1869-1881. https://doi.org/10.13031/2013.11438

Stone, K. C., \& Sadler, E. J. (2016). Assessing spatial variation of corn response to irrigation using a Bayesian semiparametric model. Trans. ASABE, 59(1), 251-261. https://doi.org/10.13031/trans.59.10942

Stone, K. C., Bauer, P. J., \& Sigua, G. C. (2019). Potential water conservation using site-specific variable-rate irrigation. Appl. Eng. Agric., 35(6), 881-888. https://doi.org/10.13031/aea.13108

Stone, K. C., Bauer, P. J., Busscher, W. J., Millen, J. A., Evans, D. E., \& Strickland, E. E. (2015). Variable-rate irrigation management using an expert system in the eastern coastal plain. Irrig. Sci., 33(3), 167-175. https://doi.org/10.1007/s00271-0140457-x

Sui, R., \& Yan, H. (2017). Field study of variable-rate irrigation management in humid climates. Irrig. Drain., 66(3), 327-339. https://doi.org/10.1002/ird.2111

Sui, R., O’Shaughnessy, S. A., Evett, S. R., Andrade-Rodriguez, A., $\&$ Baggard, J. (2020). Evaluation of a decision support system for variable-rate irrigation in a humid region. Trans. $A S A B E$, 63(5), 1207-1215. https://doi.org/10.13031/trans.13904

Thompson, R. B., Gallardo, M., Valdez, L. C., \& Fernandez, M. D. (2007). Determination of lower limits for irrigation management using in situ assessments of apparent crop water uptake made with volumetric soil water content sensors. Agric. Water Mgmt., 92(1), 13-28. https://doi.org/10.1016/j.agwat.2007.04.009

Thorp, K. R. (2020). Long-term simulations of site-specific irrigation management for Arizona cotton production. Irrig. Sci., 38(1), 49-64. https://doi.org/10.1007/s00271-019-00650-6

Thorp, K. R., \& Dierig, D. A. (2011). Color image segmentation approach to monitor flowering in lesquerella. Ind. Crops Prod., 34(1), 1150-1159. https://doi.org/10.1016/j.indcrop.2011.04.002

Thorp, K. R., Hunsaker, D. J., Bronson, K. F., Andrade-Sanchez, P., \& Barnes, E. M. (2017). Cotton irrigation scheduling using a crop growth model and FAO-56 methods: Field and simulation studies. Trans. ASABE, 60(6), 2023-2039. https://doi.org/10.13031/trans. 12323

Thorp, K. R., Thompson, A. L., \& Bronson, K. F. (2020). Irrigation rate and timing effects on Arizona cotton yield, water productivity, and fiber quality. Agric. Water Mgmt., 234, article 106146. https://doi.org/10.1016/j.agwat.2020.106146

Vellidis, G., Tucker, M., Perry, C., Kvien, C., \& Bednarz, C. (2008). A real-time wireless smart sensor array for scheduling irrigation. Comput. Electron. Agric., 61(1), 44-50. https://doi.org/10.1016/j.compag.2007.05.009

Vories, E., O'Shaughnessy, S., Sudduth, K., Evett, S., Andrade, M., \& Drummond, S. (2021). Comparison of precision and conventional irrigation management of cotton and impact of soil texture. Prec. Agric., 22(2), 414-431. https://doi.org/10.1007/s11119-020-09741-3

Walter, I. A., Allen, R. G., Elliott, R., tenfisu, D., Brown, P., Jensen, M. E., ... Wright, J. L. (2005). The ASCE standardized reference evapotranspiration equation. Reston, VA: ASCE Environmental and Water Resources Institute.

Zhang, Y., \& Schaap, M. G. (2017). Weighted recalibration of the Rosetta pedotransfer model with improved estimates of hydraulic parameter distributions and summary statistics (Rosetta3). J. Hydrol., 547, 39-53. https://doi.org/10.1016/j.jhydrol.2017.01.004 